\begin{abstract}
Title of dissertation: $\quad$ TIME INCONSISTENCY

IN THE CREDIT CARD MARKET
\end{abstract}

Haiyan Shui, Doctor of Philosophy, 2004

$\begin{aligned} \text { Dissertation directed by: } & \text { Professor Lawrence M. Ausubel } \\ & \text { Department of Economics } \\ & \text { Professor John Rust } \\ & \text { Department of Economics }\end{aligned}$

Does consumer behavior exhibit time inconsistency? This is an essential, yet difficult question to answer. This dissertation attempts to answer this question based on a large-scale randomized experiment in the credit card market. Specifically, we apply both time consistent preferences (exponential) and time inconsistent preferences (hyperbolic) to study two puzzling phenomena in the experiment.

The two puzzling phenomena seem to suggest time inconsistency in consumer behavior. First, more consumers accept an introductory offer that has a lower interest rate with a shorter duration than a higher interest rate and a longer duration. However, ex post borrowing behavior reveals that the longer duration offer is better, because respondents keep on borrowing on the credit card after the introductory period. Second, consumers are reluctant to switch, and many of those consumers who have switched before fail to switch again later.

A multi-period model with complete information is studied analytically, which shows that standard exponential preferences cannot explain the observed behavior because they are time consistent. However, hyperbolic preferences that are time inconsistent come closer to rationalizing the observed behavior. In particular, two special cases of hyperbolic discounting are carefully examined, sophisticated and naive. Sophisticated consumers prefer the short offer because it serves as a self- 
commitment device. Naive consumers prefer the short offer because they underestimate their future debt.

To further explore the possibility of explaining observed behavior by exponential preferences, we study a dynamic model in which realistic random shocks are incorporated. Estimation results show that consumers have severe self-control problem with a present-bias factor $\beta=0.8$. It is also shown that the average switching cost is $\$ 150$. With the estimated parameters, the dynamic model can replicate quantitative features of the data. 


\title{
Time Inconsistency in the Credit Card Market
}

\author{
by
}

Haiyan Shui

Dissertation submitted to the Faculty of the Graduate School of the University of Maryland, College Park in partial fulfillment of the requirements for the degree of

Doctor of Philosophy

2004

Advisory Committee:

Professor Lawrence M. Ausubel, Chair

Professor John Rust, Co-Chair

Professor John Shea

Professor Ginger Jin

Professor Haluk Unal 
(c) Copyright by

Haiyan Shui

2004 


\section{DEDICATION}

To my family and to the past memorable years in Maryland. 


\section{ACKNOWLEDGMENTS}

First of all, I would like to express my gratitude to my advisor, Professor Lawrence M. Ausubel, who introduced me to the intriguing credit card market and generously shared his insights with me. I am grateful for all the support I have received while researching and writing up this dissertation. I am also much indebted to Professor John Rust who have taught me how to use dynamic programming to investigate economic questions. During the last four years, his door has always been open to me for discussions or advice and his amiable personality has made it such a pleasure to learn from and work with him.

I feel extremely grateful to Professor John Shea, with whom I have had extensive and stimulating discussions. Some of the discussions have directly led to useful results which are included in this thesis. I also owe my gratitude to Professor Ginger Jin for critical reading on my manuscripts including this thesis and making constructive suggestions. Thanks are also due to Professor Haluk Unal for spending his time serving as the dean's representative in the committee and reviewing my thesis. Professor Robert Schwab can not be left out here. As the program director, he helped me greatly in the early days of my graduate life.

Finally, there are all the administrative staff in the Economics department who were always cheerful guides in going through the drudgeries of the university maze of paperwork. 


\section{TABLE OF CONTENTS}

List of Figures $\quad 1$

List of Tables $\quad 2$

1 Introduction $\quad 3$

2 Studies of Time Discounting 9

3 A Unique Dataset $\quad 16$

4 A Multi-period Complete Information Model 24

4.1 Time preferences and Model Set-up . . . . . . . . . . . . . . 25

4.2 "Rank Reversal" . . . . . . . . . . . . . . . . . . . . . . 28

4.2.1 "Rank Reversal" Impossible for Exponential Agents . . . . . . 29

4.2.2 "Rank Reversal" Possible for Hyperbolic Agents . . . . . . . . 31

5 A Multi-period Incomplete Information Model 36

5.1 Model Setup . . . . . . . . . . . . . . . . . . 37

5.2 Numerical Simulation and Model Prediction . . . . . . . . . . . . . 40

6 Estimation $\quad 49$

6.1 Estimation Strategy _ . . . . . . . . . . . . . . . . . . . . . 49

6.2 Estimation Results . . . . . . . . . . . . . . . . . 53 
6.3 Robustness ............................ 58

$\begin{array}{lll}7 & \text { Conclusion } & 61\end{array}$

A Sign of $\frac{d A_{1}}{d \beta_{1}} \quad \mathbf{6 4}$

B Income Process

$\begin{array}{ll}\text { Bibliography } & 67\end{array}$ 


\section{LIST OF FIGURES}

3.1 Medians of borrowers' debt over time for six market cells. . . . . . . . 21

3.2 Borrowing frequencies of respondents over time for six market cells. . 23

4.1 Generalized time preferences. . . . . . . . . . . . . . . 26

4.2 Rank reverse area of Sophisticated and Naive Hyperbolic Agents . . . 34

5.1 Policy functions. The asset choice $A_{t+1}$ is a function of cash-on-hand at period $t, X_{t}$, for different $\beta$ s. . . . . . . . . . . . 41

5.2 Policy functions. The asset choice $A_{t+1}$ is a function of cash-on-hand at period $t, X_{t}$, when $\beta=0.5 \ldots \ldots \ldots$. . . . . . . . . 42

5.3 Simulated mean debt among borrowers in market cell A for the exponential model. . . . . . . . . . . . . . . . . . . . . . . . 44

5.4 Simulated mean debt among borrowers in market cell A for the sophisticated hyperbolic model. . . . . . . . . . . . . . . . . 45

5.5 Simulated mean debt among borrowers in market cell $\mathrm{A}$ for the naive hyperbolic model. This is the actual borrowing not expected. . . . . . 46

6.1 Simulated debt moments. The triangle line is the empirical data. The solid line, the dash line and the dotted line are predicted by the exponential, sophisticated and naive hyperbolic models respectively. . 56 


\section{LIST OF TABLES}

3.1 Sample statistics. Standard deviations are in parentheses. Sample statistics for all six market cells are reported under "All" to save space. Due to randomization, the statistics are similar across different market cells. . . . . . . . . . . . . . . . . . . 18

3.2 Empirical rank reversal. Standard deviations are in parentheses. the calculated effective interest rate for market cell F (8.32\%) slightly exceeded the stated APR of $7.9 \%$ because some customers went delinquent and lost the introductory rate. . . . . . . . . . . . . . 20

5.1 Response rates for different time preferences. Response is based on 10,000 simulations. $\beta, \delta$ are discount factors. $\delta=0.9999$ for both hyperbolic models. Other parameters are assumed to be the the same for all three models. $k$, the switching cost parameter, is assumed to be 0.03 . Mean of $A_{1}$ is 5000 and variance is $8 \mathrm{e} 6$, which is liquid assets at the time of solicitation. . . . . . . . . . . . . . . 4 47

6.1 Estimated parameters. Standard errors are in parentheses. . . . . . . 54

6.2 Simulated response in six market cells for hyperbolic and exponential models. . . . . . . . . . . . . . . . . 57

6.3 Robustness. . . . . . . . . . . . . . . . . . . 60 


\section{Chapter 1}

\section{Introduction}

The exponential discounted utility model (DU) proposed by Samuelson (1937) is a standard theoretical model for consumer intertemporal choices. The central assumption of the DU model is that consumer intertemporal impatience can be condensed into one parameter, a constant discount rate per period. Constant discounting implies that consumers' intertemporal preferences are time consistent.

A significant body of evidence, however, has been gathered in experimental psychology and economics studies, that consumers have a declining rate of time preferences. Researchers find that a hyperbolic functional form, which imposes declining discount rates, fits such experiment data much better that the exponential function. Declining discount rates imply that consumers are time inconsistent.

Motivated by experiments, economists have studied implications of declining discount rates in various economic settings, such as procrastination, retirement, addiction and credit card borrowing. ${ }^{1}$ They have developed a particular simple functional form, a quasi-hyperbolic function. This mathematical formulation is highly tractable and captures the essence of hyperbolic discounting, a declining discount rate. We shall simply refer it as hyperbolic discounting in later discussion.

\footnotetext{
${ }^{1}$ See Akerlof (1991), Diamond and Koszegi (2003), Gruber and Koszegi (2001), Harris and Laibson (2001), Laibson (1997), Laibson et al. (1998), O’Donoghue and Rabin (1999, 2001).
} 
Regardless of substantial theoretical work, the hyperbolic discounting is criticized for lack of convincing empirical evidence. The credibility of laboratory response is questionable. And field evidence is very hard to come by. Since the essential difference between exponential and hyperbolic discounting is time consistency, an ideal test is to compare consumers' long run plans with their later actions. The plans are determined by their expected future time preferences, however the actions are determined by their current preferences, which will be consistent for exponential consumers, however inconsistent for hyperbolic consumers.

In our study we have access to a market experiment, which is an almost ideal test. In the experiment, 600,000 consumers are randomly mailed one out of six different credit card offers, denoted as Market Cell A to F. The six offers have different introductory interest rates and different durations: Market Cell A (4.9\% for 6 months), B (5.9\% for 6 months), C (6.9\% for 6 months), D (7.9\% for 6 months), E (6.9\% for 9 months) and F (7.9\% for 12 months). All other characteristics of the solicitations are identical across the six market cells. Consumer responses and subsequent usage of respondents for 24 months are observed.

One advantage of this experiment is that the 600,000 subjects do not change their behavior due to their participation in the experiment; indeed, they do not even know that they are part of an experiment. A second advantage of this experiment is that consumer long-run plans are inferred from their actions. Consumer plans are identified from their responses to different offers, such as A (4.9\% for 6 months) and F (7.9\% for 12 months). For example, if the consumers who receive the short introductory offer (A) are more likely to accept the credit card than those who receive the longer introductory offer $(\mathrm{F})$ - and, given the randomized experimental treatment, the two groups may be viewed as identical — it implies that the consumers expect their credit card debt to be short-lived. For purposes of inferring experimental subjects' long-run plans, actions speak much louder than words. A third advantage of this experiment is that the number of experimental subjects $(600,000$ 
consumers solicited, and more than 5,000 consumers accepting the solicitation) is quite large, ensuring that the inferences drawn will be precise. Combining the subjects' inferred plans with their later actions, we have a unique opportunity to test for time consistency.

There are two phenomena in this dataset suggestive of time inconsistency. First, significantly more consumers in Market Cell A are found to accept their offers than in Market Cell F. This ex ante preference becomes puzzling after observing that respondents, ex post, keep on borrowing on this card well after introductory periods. We will show in a later chapter that respondents in Market Cell A would pay less interest if their cards were repriced as offer F. Why do not all their counterparts in Market Cell F accept the F offer? We term the first puzzle as "rank reversal." Second, consumer switching behavior is not consistent over time. The majority of respondents $(60 \%)$ stay with this card after the introductory period, and their debts remain at the same level as when they accepted this card. Given the same debt level, it should be worthwhile to switch a second time since it was optimal to accept this offer before. Obviously, there would be no puzzle if respondents did not receive new low-rate solicitations from other credit card issuers after the end of the introductory period. However, the number of solicitations averaged at least three per qualified household per month during the sample period. A typical solicitation from the observed issuer (and other credit card issuers contemporaneously) included a $5.9 \%$ introductory interest rate for 6 months. $96 \%$ of the respondents remain credit-worthy after 6 months, which will be discussed in greater detail in Chapter 3 .

At least two explanations are possible for consumer behavior that on the surface appears to be time inconsistent. First, consumers may behave in a time inconsistent fashion because they have hyperbolic time preferences. Hyperbolic consumers have a much higher discount rate in the short run than in the long run. Therefore their credit card choice, which is largely determined by short-run benefit, may not be optimal from the long-run perspective. Second, consumers are subject 
to random shocks, the ex post realizations of which may generate divergences between consumers' initial plans and later actions, even if their preferences are time consistent.

In this dissertation, we examine the validity of both hypotheses. To build up a basic intuition, we analyze a multi-period credit card choice model without uncertainty. The simple model shows that exponential consumers will never exhibit "rank reversal". Exponential agents always prefer an offer requiring less interest payment. This is due to their time consistency, which makes their short-run choice (credit card choice) also optimal from the long-run perspective (later interest payment). However, "rank reversal" is possible for hyperbolic consumers. There are two kinds of hyperbolic preferences which have been widely studied in the literature: sophisticated and naive. Our studies show that both versions are able to explain "rank reversal", even though the underlying economic stories are different. A sophisticated hyperbolic consumer who recognizes her time inconsistency problem would like to precommit to avoid overspending in the future. Accepting a shorter introductory offer, rather than a longer one, serves as a commitment device, even though she would pay less interest if she accepted the longer offer. A naive hyperbolic consumer, however, trades a longer offer for a shorter one because she underestimates the amount she will borrow in the future. This underestimation is due to the fact that she naively believes that her future selves will be as patient as she desires now.

To explore the possibility of explaining behavior with random shocks, we develop a dynamic model which incorporates three important random processes. First, consumer income has both persistent and transitory shocks. Second, receiving new introductory offers is probabilistic. Third, accepting a new offer causes the consumer to incur a random switching cost. A realistic dynamic model is required because some researchers argue that exponential discounting can explain anomalies if "even a small degree of" uncertainty is incorporated, for example Fernandez-Villaverde and Mukherji(2002), which we show is not necessarily the case here. 
We find that an exponential model still cannot reconcile respondents' continued borrowing and preference for the shorter offer A, even with random shocks. The intuition for the failure is that the behavioral discrepancy observed is not for some individuals but for a large group of consumers. An individual exponential consumer may, ex ante, accept an offer that proves, ex post, to be a bad deal based on the realized random shocks. However, a relatively large group of exponential consumers should prefer the offer that on average provides the lowest interest payment. Hyperbolic time preferences are also incorporated into the dynamic model, from which we estimate time preference parameters with a reasonable degree of precision.

Estimation results show that the second puzzle can only be explained by the stochastic nature of switching costs, which are traditionally assumed to be constant for an individual. Our random switching cost appears to be a more realistic treatment, because it captures either fluctuations in free time or fluctuations due to subjective, psychological factors that strongly affect realized switching costs. Under this interpretation, respondents in this experiment accept the offers due to their low realized switching costs at the time of solicitation. However, their mean switching costs are much higher, which can be partially inferred from the low response rate (1\%). This high mean will keep the majority of respondents from switching a second time after the introductory period.

Another interesting finding is that sophisticated and naive hyperbolic models behave alike when $\beta$ is close to 1 . Our estimated $\beta$ equals to 0.8 under which the two models are not distinguishable. This finding is worth mentioning because sophisticated models are much more difficult to compute than naive models. Since sophisticated agents know that they have different time preferences at different time points, they essentially play a dynamic game between intertemporal selves. Therefor the sophisticate model faces standard difficulties around dynamic games, such as multiple equilibria. On the other hand, naive models are as easy as exponential models. Computation doesn't involve strategic choices between intertemporal selves 
because naive agents don't know they are time inconsistent. Since they behave similar under empirical relevant parameters, it is reasonable to use naive models to approximate sophisticated models in positive analysis.

This thesis is organized as follows. In Chapter 2 we give a review of previous theoretic and empirical studies of intertemporal discounting. In Chapter 3, the unique dataset is introduced and interesting phenomena are elaborated. Chapter 4 will analyze a complete information model, which illustrates that the interesting phenomena are puzzling under exponential discounting. The dynamic model with incomplete information, which accommodates both exponential and hyperbolic time preferences, is presented in Chapter 5. The estimation strategy and results are discussed in Chapter 6. Lastly, we conclude this study in Chapter 7. 


\section{Chapter 2}

\section{Studies of Time Discounting}

Intertemproal choices, decisions involve tradeoffs among costs and benefits occurring at different time, are important and ubiquitous. Such decisions not only affect one's wealth, but may also, as Adam Smith first recognized, determine the economic prosperity of nations.

Jonh Rae's The Sociology Theory of Capital discusses the underlying psychologic motives, which determines a nation's " the effective desire of accumulation", which in turn decides a society's level of saving. He believed that intertemporal choices was the joint product of four factors, two promoting and the other two limiting the desire of saving. The two main factors which promoted the desire are the bequest motives and the propensity to exercise self-restraint. One limiting factor is the uncertainty of human life. The second factor that limited the effective desire was the excitement of immediate consumption.

Eugen von Bohm-Bawerk began modeling intertemporal choices in the same terms as other economic tradeoffs, as a 'technical' decision about allocating resources over different points of time, much as one would allocate resources between housing and food. This treatment was formalized by Irving Fisher. Fisher plotted the intertemporal consumption decision on a two-good indifference diagram, with current consumption on the abscissa and the second period consumption on the ordinate. 
This representation made clear that a person's intertemporal allocation depends on both time preferences and diminishing marginal utility. Pure time preference can be interpreted as the marginal rate of substitution on the diagonal where consumption is equal in both periods.

In 1937, Paul Samuelson introduced the DU model. He intended to offer a generalized model of intertemporal choices applicable to multiple time periods. Fisher's graphical indifference-curve analysis was difficult to extend to more than two periods. In this general model, all psychological concerns underlying time preferences were condensed into a single parameter, the discount rate.

The DU model assumes a person's intertemporal utility function can be described by the following functional form:

$$
U^{t}\left(c_{t}, \ldots, c_{T}\right)=\sum_{k=0}^{T-t} D(k) u\left(c_{t+k}\right), \text { where } D(k)=\delta^{k} .
$$

$u\left(c_{t+k}\right)$ is the person's cardinal instantaneous utility function and $D(k)$ is the person's discount function, the relative weight she attaches in period $t$ to her well-being in period $t+k$. The constant $\delta$ is the pure rate of time preference which is meant to reflect the collective effects of the four "psychological" motives discussed above.

The DU model has since been widely adopted as the standard framework of choice for analyzing intertemporal decisions, because it has provided simple but successful explanations of observed economic phenomena. However legitimacy of the DU model has long been questioned by some researchers. Strotz (1956) was the first to consider alternatives to exponential discounting. He pointed out that there is no reason why an individual should have such a special discount function. Based on his casual observation, he suggested that special attention should be given to the case of declining discount rates. Moreover, he showed that a person would have time inconsistent preferences for any discount functions other than exponential. He proposed two strategies that might be employed by a person who foresees her inconsistency: the strategy of precommitment (she commits to some plan of action) and 
the strategy of consistent planning (she modifies her current action to accommodate future actions).

More recent laboratory experiments show that subjects have a declining rate of time preference, for example, Ainslie and Haendel (1983), Loewenstein and Thaler (1989) and Thaler (1981). In Ainslie and Haendel (1983), experimental subjects are asked the following two questions:

Question1:Would you rather receive $\$ 50$ today or $\$ 100$ in 6 months?

Question2:Would you rather receive $\$ 50$ in one year or $\$ 100$ in 1 year plus 6 months?

Many subjects chose the smaller-sooner reward in the first question and the largerlater reward in the second. This phenomenon has been termed as "preference reversal." as empirical evidence against exponential discounting. The argument is that subjects apparently apply a larger discount rate for a six-month delay as the delay becomes closer, while exponential time preferences assume that consumers use the same discount rate for any equal-distance period.

Motivated by the laboratory evidence, Laibson and his collaborators have developed a simple functional form ${ }^{1}$, which captures the essence of hyperbolic discounting:

$$
D(k)=\left\{\begin{array}{cc}
1 & \text { if } k=0 \\
\beta \delta^{k} & \text { if } k>0
\end{array} .\right.
$$

Using this simple $(\beta, \delta)$ formulation, they have explored the implication of hyperbolic discounting under different economic settings.

Akerlof (1991) applies it to rationalize procrastination and cult obedience. Laibson (1997) analyzes a model where hyperbolic consumers have access to a limited commitment tool: an illiquid asset. That model is able to explain why consumers have asset-specific marginal propensities to consume. Laibson and et. al (1998) calibrate a hyperbolic model to evaluate the efficacy of tax-deferred saving instruments, such as 401(k) plan. O' Donoghue and Rabin (1999) is the first to dis-

\footnotetext{
${ }^{1}$ Phelps (1968) first used this function to model "imperfectly altruistic" across generations.
} 
tinguish between two kinds of hyperbolic discounting, sophisticated and naive. They find these two models behave quite differently when facing two kinds of activities, one involving immediate cost and the other immediate benefit. Naive people procrastinate activities with immediate costs and preprope immediate-benefit activities. Sophisticated mitigates procrastination but exacerbates preproperation. Diamond and Koszegi (1999) explores hyperbolic consumers' saving and retirement decisions. Gurber and Koszegi (1999)estimate the optimal tax for cigarettes when people have hyperbolic preferences. Imrohoroglu et. al (2000) examine the role of social security in an economy where consumers have time inconsistent preferences. Della Vigna and Malmendier (2003) analyzes the optimal contract design of firms when consumers have time-inconsistent preferences. Like O' Donoghue and Rabin (1999), they consider two types of goods, investment goods which involves immediate cost and leisure goods which involves immediate benefit. They find that firms will price investment goods below marginal costs and above marginal costs for leisure goods.

Despite the surge of interest, some researchers challenge the validity of the experimental evidence which are commonly cited to justify hyperbolic discounting. Fernandez-Villaverde and Mukerji (2002) explain the above "preference reversal" by uncertainty. They argue that when comparing payments between today and 6 months later. Uncertainty will reduce the attractiveness of the future payment but not today's. However, when comparing two future payments, one year and one and half year, the uncertainty is relevant for both. The two questions are not equivalent, hence the preference change doesn't necessarily support hyperbolic discounting. Actually, some experiments have been conducted, where equivalent questions were asked and consumers were still found to have a declining discount rate. For example, in Benzion, Rapoport and Yagil (1989), researchers solicit subjects' willingness to pay to expedite a payment of $\$ 100$ for different time delays, 0.5, 1, 2 and 4 years. In this experiment, subjects are comparing today's payment with different future payments, which should be comparable. Rubinstein (2003) provides another deci- 
sion theory to explain laboratory observations. Bershorov and Coffey (2003) give a comprehensive review of laboratory experiments. They argue that experiments which give subjects money at different time periods cannot distinguish hyperbolic from exponential time preferences because both preferences will maximize wealth. Based on this argument, the only possible way to identify hyperbolic discounting is nonfinancial rewards. However, utilities from goods or service may vary as the environment change, not necessarily preference change. Our study shows that, contrary to Bershorov and Coffey (2003), there exists financial experiments which can separate exponential and hyperbolic preferences.

The essential difference between an exponential and hyperbolic consumer is that whether "current self" and "future self" agree on the desired discount factor in the future, not whether the discount factor is exactly the same for any equaldistance period. An exponential consumer has the same discount factor $(\delta)$ between period $t$ and $t+1$ no matter which period she is at. However, a hyperbolic consumer has a discount factor $\delta$ between period $t$ and $t+1$ at period $\tau<t$, and a discount factor $\beta \delta$ at period $t$. Because of this, a hyperbolic consumer would like to revise her consumption plan made at period $\tau<t$ when period $t$ arrives. This revision does not exist in the exponential model. Therefore, to identify hyperbolic discounting, it is vital to solicit consumer time preferences dynamically.

Several dynamic experiments have been studied, such as in Read and van Leeuwen (1998). Subjects are asked to choose between healthy and unhealthy food both in advance and immediately before the snacks are given. They find that subjects are more likely to make the unhealthy choice when asked immediately before the snacks are given than when asked a week in advance. However, this evidence is also questionable that subjects may not tell the truth when they are first asked, because they know they can always change their mind later.

As mentioned in Chapter 1, in our market experiment we can infer consumer long-run plans from their relative preference between a lower but shorter introduc- 
tory offer and a higher however longer offer, which reveals the preference of "current self". We also observe their subsequent actual behavior, which reveals preference of "future self". By comparing the two, we can identify time inconsistent preferences. And since consumers face financial rewards, we don't face the same interpretation difficulty as that in experiments of nonfinancial rewards.

Recently, some researchers start to collect field evidence for consumer time preferences. They have analyzed consumer behavior in different markets, such as the credit card market (Laibson, Repetto and Tobacman (2000)), the health club market (Della Vigna and Malmendier (2001)), and the labor market (Fang and Silverman (2001), Paserman (2001)).

Among them, the most related one is Della Vigna and Malmendier (2001), which utilizes a similar identification strategy. They identify consumer time inconsistency by comparing their initial contractual choices among an annual contract, a monthly contract and a pay-per-visit, with their later actual attendance. They find that members who choose a monthly contract with a fee of $\$ 70$ attend on average 4.8 times per month. They pay more than $\$ 17$ per visit even though a $\$ 10$-per-visit fee is also available. They use a (partially) naive hyperbolic models to explain this puzzle. In the study, they focus on first-time users. The inexperienced users may choose the wrong contract because they have incorrect expectations about their future attendance. Actually they find strong evidence that club members learn over time: they switch to a more appropriate contract given their actual attendance. An experienced sample is very important when identifying consumer time-inconsistency from their behavior at different dates. In Chapter 3 we will show that consumers in our sample are very familiar with credit card offers.

Another interesting study is Laibson et. al (2000), which attempt to reconcile the high frequency of credit card borrowing with high level wealth accumulation. They find that an exponential model which matches the wealth level predicts only $20 \%$ population borrow on credit cards, far less than the empirical data $60 \%$. After 
allowing for hyperbolic discounting, the model prediction matches observed data much better. 


\section{Chapter 3}

\section{A Unique Dataset}

A substantial portion of credit card marketing today is done via direct-mailed preapproved solicitations. The typical solicitation includes a low introductory interest rate for a known duration, followed by a much higher post-introductory interest rate. Sophisticated card issuers decide on the terms of their solicitations by conducting large-scale randomized trials. The dataset used is results of such a "market experiment" conducted by a major United States issuer of bank credit cards in 1995. The issuer generated a mailing list of 600,000 consumers and randomly assigned the consumers into 6 equal-sized market cells (A-F). The market cells have different introductory offers as mentioned above but are otherwise identical (including the same post-introductory interest rate of $16 \%$ ).

In each market cell, between 99860 and 99890 observations are actually obtained, out of the 100,000 consumers. About half of the missing observations are due to one known data problem: the approximately $5 \%$ of the individuals who have responded to the preapproved solicitation but are declined (due to a deterioration of credit condition or failure to report adequate information or income) are deleted from the dataset for unknown reasons. Nevertheless, over $99.8 \%$ of the sample is still included. Ausubel (1999) has offered statistical evidence that this is still a good random experiment among the remaining observations. Financial statistics of 
the remaining 599,257 consumers are observed at the time of solicitation and their responses to their offers are recorded.

For consumers who accepted their credit offers (respondents) we observe great details about their monthly account activities for subsequent 24 months. For a month $t$, we observe the amount that the account has paid at the beginning, the amount it has charged during the month, any finance charge (such as interest payment, late-payment fee and over-credit-limit fee) and the total balance owed at the end. Based on the information, we distinguish credit card debt from convenience charges, for which no interest is billed. In later analysis, we will focus on debt.

Besides the quantitative measures, we also observe two interesting qualitative measures. The first measures the delinquency status: whether the account is delinquent this month or not and the duration of the delinquency. The second measures whether the account owner has filed for a personal bankruptcy or not. These two measures offer important information about the account credit status over time.

Important financial statistics of the whole sample and respondents are reported in Table (3.1). "Months on File" is the number of months a consumer has been with the credit bureau. "Number of Past-due" is the number of 30-day past-due in last 12 months. "Revolving Balance" is the total balance on those revolving accounts, composed of convenience charges incurring no interest payments and debt. "Revolving Limit" is the total credit limit a consumer has on her revolving accounts. ${ }^{1}$ Most observables of respondents are statistically worse than the whole sample. Nevertheless, both groups are established good credit risk. Majority of consumers have more than ten-year credit history. Every consumer has at least one existing credit card and $75 \%$ have more than two credit cards. They are good risk because very few have been past due in last two years, which is shown in "Number of Past-due". And none of them has had a sixty-day past-due, which is considered to be a severe

\footnotetext{
${ }^{1}$ Revolving accounts are the accounts on which consumers can borrow with no prespecified repayment plan. The majority of revolving accounts are credit cards.
} 


\begin{tabular}{|c|c|c|c|c|c|c|c|}
\hline & $\mathrm{N}$ & $\begin{array}{c}\text { Months On } \\
\text { File }\end{array}$ & $\begin{array}{c}\text { Number of } \\
\text { Past-due }\end{array}$ & $\begin{array}{c}\text { Revolving } \\
\text { Balance }\end{array}$ & $\begin{array}{c}\text { Revolving } \\
\text { Limit }\end{array}$ & $\begin{array}{c}\text { Number of } \\
\text { Credit Cards }\end{array}$ & Income \\
\hline All & 599,257 & 174 & 0.0197 & $\$ 2,509$ & $\$ 17,481$ & 3.77 & NA \\
& $(71)$ & $(0.139)$ & $(4058)$ & $(11388)$ & $(1.88)$ & \\
\hline A & 1073 & 126 & 0.0308 & $\$ 3,927$ & $\$ 15,473$ & 3.94 & $\$ 44,180$ \\
& & $(76)$ & $(0.1727)$ & $(4979)$ & $(10573)$ & $(2.057)$ & $(24051)$ \\
\hline B & 903 & 128 & 0.0266 & $\$ 3,474$ & $\$ 15,137$ & 3.81 & $\$ 43,170$ \\
& & $(79)$ & $(0.1609)$ & $(4725)$ & $(11112)$ & $(2.101)$ & $(25175)$ \\
\hline C & 687 & 114 & 0.0247 & $\$ 3,543$ & $\$ 14,230$ & 3.598 & $\$ 42,253$ \\
& & $(77)$ & $(0.1555)$ & $(4901)$ & $(11268)$ & $(2.068)$ & $(24437)$ \\
\hline D & 645 & 112 & 0.0248 & $\$ 3,584$ & $\$ 14,075$ & 3.557 & $\$ 41,215$ \\
& & $(76)$ & $(0.1557)$ & $(4988)$ & $(11703)$ & $(2.07)$ & $(25274)$ \\
\hline E & 992 & 125 & 0.0363 & $\$ 3,694$ & $\$ 15,176$ & 3.729 & $\$ 43,830$ \\
& & $(76)$ & $(0.1871)$ & $(5066)$ & $(11313)$ & $(2.076)$ & $(28733)$ \\
\hline F & 944 & 123 & 0.0222 & $\$ 4,042$ & $\$ 15,107$ & 3.807 & $\$ 43,697$ \\
& & $(77)$ & $(0.1476)$ & $(5469)$ & $(10688)$ & $(1.98)$ & $(26725)$ \\
\hline
\end{tabular}

Table 3.1: Sample statistics. Standard deviations are in parentheses. Sample statistics for all six market cells are reported under "All" to save space. Due to randomization, the statistics are similar across different market cells. 
delinquency. Their good credit quality can also be inferred from their high revolving limit and low revolving balance. For a better description, a utilization rate is introduced, defined as the ratio of revolving balance to its limit. The average utilization rate for the whole sample is only $16 \%$ and for respondents only $27 \%$. Good credit risk generally receive many solicitations every month, especially when they have a long credit history.

There are two puzzling phenomena observed in this dataset. The first puzzle is that significantly more consumers in Market Cell A (4.9\% for 6 months) accept their offers than in Market Cell F (7.9\% for 12 months). However, respondents keep on borrowing on this card after six months. Based on ex post interest payment offer F should have a higher response rate than offer A. This phenomenon is called "rank reversal". Consumer responses are recorded in the third column of Table (3.2). Only about one percent consumers accept their credit card offers, which is also the average response rate for the whole economy in the sample period. ${ }^{2}$ Significantly more consumers accept the shorter offer A than the longer offers, E (6.9\% for 12 months) and F, based on the T-test. This preference is suboptimal if one compares the effective interest rates under different offers. The effective interest rate is the annual interest rate respondents actually pay in each market cell, which equals the ratio of the total interest payment to the total credit card debt and is shown in the fifth column of Table (3.2). The effective interest rate is two percentage points lower in Market Cell F than in Market Cell A and one percentage point lower in Market Cell E. Since the average debt among borrowers is $\$ 2500$, an average borrower in Market Cell A pays $\$ 50$ more interest than in Market Cell F and $\$ 25$ than in Market Cell E. To make sure this "rank reversal" phenomenon is not driven by outliers, we calculate a "what if" interest payment for each respondent. We ask how much more or less a member of Market Cell A would pay if her account were repriced according to the formula of Market Cell F. Consumer behavior is assumed unchanged under

\footnotetext{
${ }^{2}$ According to BAI Global Inc., the response rate to solicitations is $1.4 \%$ in 1995.
} 


\begin{tabular}{|c|c|c|c|c|c|}
\hline $\begin{array}{c}\text { Market } \\
\text { Cell }\end{array}$ & $\begin{array}{c}\text { Number of } \\
\text { Observations }\end{array}$ & $\begin{array}{c}\text { Effective } \\
\text { Response Rate } \\
\end{array}$ & $\begin{array}{c}\text { Rank by } \\
\text { Response Rate }\end{array}$ & $\begin{array}{c}\text { Effective } \\
\text { Interest Rate }\end{array}$ & $\begin{array}{c}\text { Rank by } \\
\text { Interest Rate }\end{array}$ \\
\hline $\begin{array}{l}\text { A: } 4.9 \% \\
6 \text { months }\end{array}$ & 99,886 & $\begin{array}{c}1.073 \% \\
(0.00033)\end{array}$ & 1 & $10.23 \%$ & 3 \\
\hline $\begin{array}{l}\text { B: } 5.9 \% \\
6 \text { months }\end{array}$ & 99,872 & $\begin{array}{c}0.903 \% \\
(0.00030)\end{array}$ & 4 & $11.35 \%$ & 4 \\
\hline $\begin{array}{l}\text { C: } 6.9 \% \\
6 \text { months }\end{array}$ & 99,869 & $\begin{array}{c}0.687 \% \\
(0.00026)\end{array}$ & 5 & $11.86 \%$ & 5 \\
\hline $\begin{array}{l}\text { D: } 7.9 \% \\
6 \text { months }\end{array}$ & 99,880 & $\begin{array}{c}0.645 \% \\
(0.00025)\end{array}$ & 6 & $12.35 \%$ & 6 \\
\hline $\begin{array}{l}\text { E: } 6.9 \% \\
9 \text { months } \\
\end{array}$ & 99,890 & $\begin{array}{r}0.992 \% \\
(0.00031) \\
\end{array}$ & 2 & $9.23 \%$ & 2 \\
\hline $\begin{array}{l}\text { F: } 7.9 \% \\
12 \text { months }\end{array}$ & 99,860 & $\begin{array}{c}0.944 \% \\
(0.00031)\end{array}$ & 3 & $8.32 \%$ & 1 \\
\hline T-TEST & & P-VALUES & & & \\
\hline A vs. E & & $7.23 \%$ & & & \\
\hline$A$ vs. $F$ & & $0.29 \%$ & & & \\
\hline
\end{tabular}

Table 3.2: Empirical rank reversal. Standard deviations are in parentheses. the calculated effective interest rate for market cell $\mathrm{F}(8.32 \%)$ slightly exceeded the stated APR of $7.9 \%$ because some customers went delinquent and lost the introductory rate. 


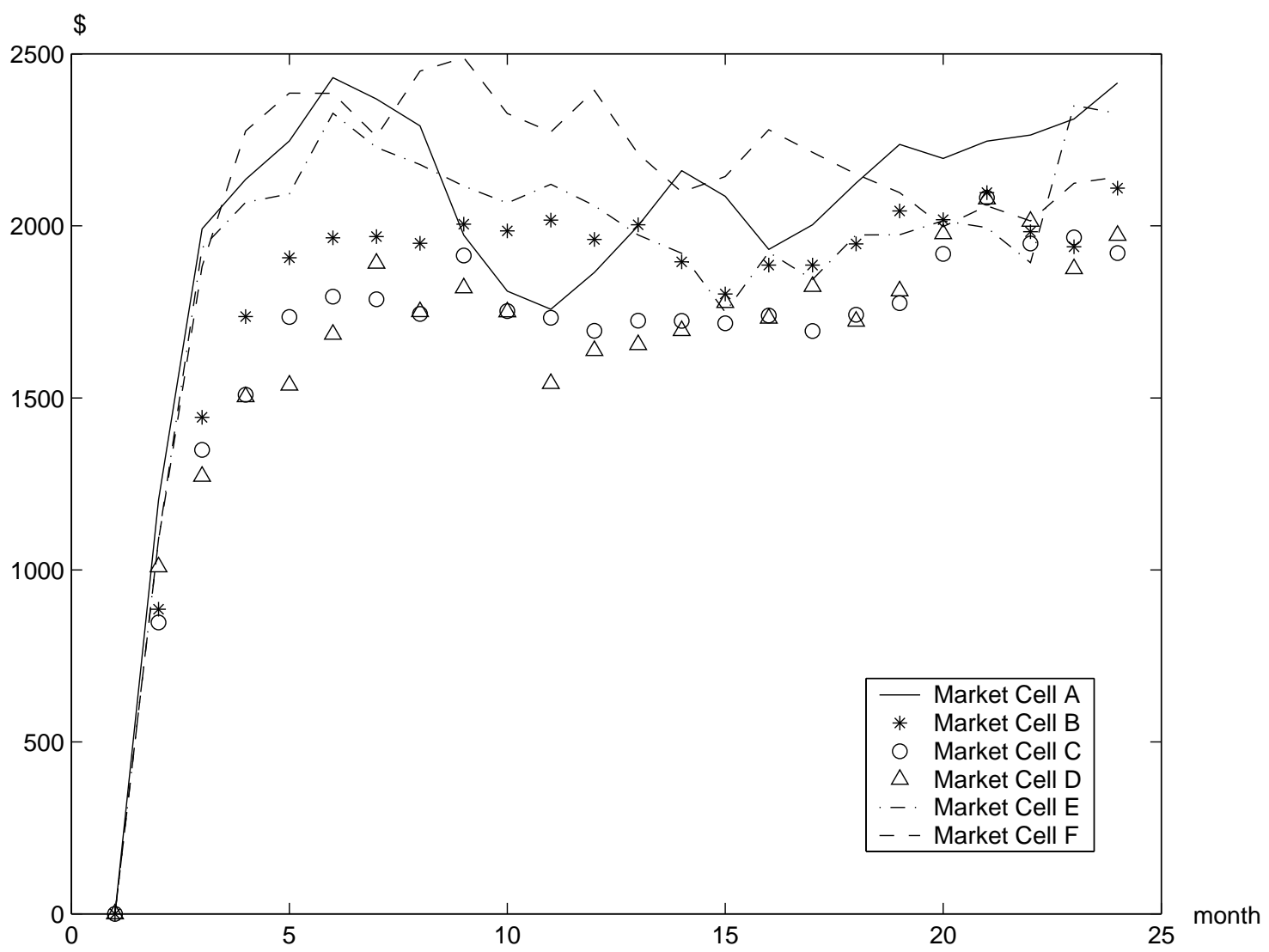

Figure 3.1: Medians of borrowers' debt over time for six market cells.

the new cell. $42 \%$ of them would save more than $\$ 10,34 \%$ would save more than $\$ 20$ and $26 \%$ would save more than $\$ 40$. Only $21 \%$ of respondents would do worse in this exercise. One thing deserves mentioning is that consumers optimally prefer the lower introductory interest rates among offers $\mathrm{A}, \mathrm{B}(5.9 \%$ for 6 months $), \mathrm{C}(6.9 \%$ for 6 months) and $\mathrm{D}(7.9 \%$ for 6 months). This seems to suggest consumers are rational and they can make the right choice when comparison involved is simple. This also makes us more confident about the quality of this random experiment.

The second puzzle is that respondents do not switch again after the introductory offer expires even though their debts remain at the same level as before. We observe a stable debt distribution over time among respondents who borrow. The 
median debt among borrowers stabilizes around $\$ 2000$ in the twenty-four months, shown in Fig.(3.1). The first quartile remains around $\$ 500$ and the third quartile is around $\$ 3500$. The proportion of respondents who borrow does not decrease much over time. As shown in Fig.(3.2), about $60 \%$ of respondents borrow during introductory periods and over 35\% continues to carry balances after two years, which is the same across all market cells. Majority of revolvers don't switch! Of course, this is not a puzzle if respondents have not received new offers after this one expires, however, this is impossible given the high volume of solicitations and the good credit quality of respondents. Credit card companies will not send a consumer new solicitations if she is either more than 60 days past-due or she declares a personal bankruptcy. Among respondents, about 1\% declare bankruptcy and 4\% experience a severe delinquency after accepting this card. Apparently, this cannot explain why $35 \%$ respondents don't switch. 


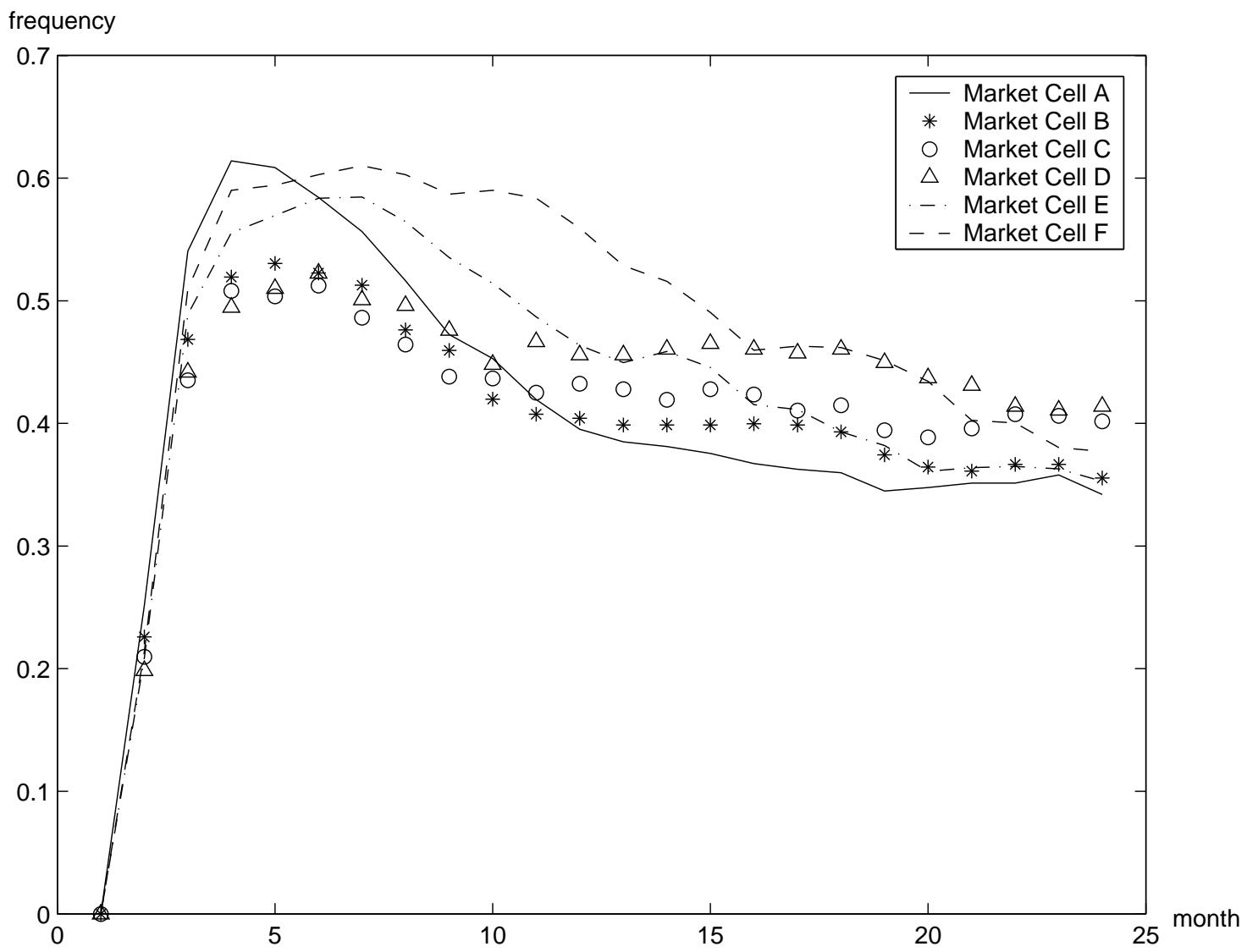

Figure 3.2: Borrowing frequencies of respondents over time for six market cells. 


\section{Chapter 4}

\section{A Multi-period Complete Information Model}

In this chapter, we will analyze a multi-period model with complete information to prove that "Rank Reversal" is impossible in an exponential model. Time consistent agents will always choose a credit offer which requires the lowest interest payment. However, this possibility exists for hyperbolic agents, both naive and sophisticated, which is illustrated by a simple three-period model. Regardless of its simplicity, the three-period model illustrates essential differences between exponential and hyperbolic models.

Besharov and Coffey (2003) conclude that hyperbolic time preferences are not identifiable using financial rewards. The reward they consider is a specific type: give a certain amount of money to agents at different dates, as is commonly observed in laboratory experiments. The model below provides a specific example that hyperbolic discounting is identifiable, if the formula of financial rewards is carefully designed. Our later estimation work based on a realistic dynamic model shows that this identification still holds, when uncertainty and liquidity constraint are incorporated. 


\subsection{Time preferences and Model Set-up}

A general time preference formulation is adopted, which is first developed in O'Donoghue and Rabin (2001). The representative agent has a current discount function of $\left\{1, \beta_{0} \delta, \beta_{0} \delta^{2}, \ldots\right\}$, where $\beta_{0}$ represents "a bias for the present" — how much the agent favors this period versus later periods and $\delta$ is a long-term discount factor.

Depending on the expected strategies, three types of hyperbolic models are special cases of this general model, two of which have been commonly studied ${ }^{1}$. The expectation of the strategies of future selves are determined by the expected discount function, which is assumed to be $\left\{1, \beta_{1} \delta, \beta_{1} \delta^{2}, \ldots\right\}$ for all subsequent periods. When $\beta_{0}=\beta_{1}=\beta<1$, the agent (sophisticate hyperbolic) has a correct expectation about her future. Self $\tau$ realizes that the discount factor between period $t$ and period $t+1$ will become $\beta \delta$ when period $t$ arrives. When $\beta_{0}<\beta_{1}=1$, the agent is called a naive hyperbolic agent since she has an incorrect expectation about her future. She naively believes that she would behave herself $\left(\beta_{1}=1\right)$ from the next period on. In between the sophisticate and naive hyperbolic agent, a partial naive agent can be defined when $0<\beta_{0}<\beta_{1}<1$. Such an agent underestimates the impatience she has in the later periods like a naive agent. However, she anticipates a difference between today's desired patience and tomorrow's actual one. In the following discussion, we will focus on the first two types of hyperbolic models.

When $\beta_{0}=\beta_{1}=1$, the general model is the standard exponential model. Exponential agents have no special preference for current period and discount any two equal-distance periods by the same discount factor $\delta$. The four models are summarized in Fig.(4.1).

\footnotetext{
${ }^{1}$ Naive and sophisticated hyperbolic models have been widely studied. Strotz (1956) and Phelps and Pollak (1968) carefully distinguished the two assumptions, and O'Donoghue and Rabin (1999) studied different theoretic implications from these two. Laibson $(1994,1996,1997)$ assumed consumers are sophisticated. On the other hard, Akerlof (1991) adopted the naive hyperbolic assumption.
} 




Figure 4.1: Generalized time preferences. 
The representative agent lives for $T$ periods. At the beginning of period $\tau$, she chooses an optimal consumption level by maximizing a weighted sum of her utilities from this period on:

$$
\max _{C_{\tau}} u\left(C_{\tau}\right)+\beta_{0} \sum_{t=\tau+1}^{T} \delta^{t-\tau} u\left(C_{t}\right),
$$

where the relative weights are determined by her current discount function. $u\left(C_{t}\right)$ is a concave instantaneous utility function.

The agent receives an income $y_{t}$ at period $t$ and she lives in a complete market, where she can borrow or save at the save gross interest rate $r_{t}$ and there is no credit limit on her credit card. ${ }^{2}$

$$
C_{t}=y_{t}-A_{t}+r_{t-1} A_{t-1}
$$

She has an initial debt $A_{0}$ at the beginning of period one. The boundary condition is that she pays off all her debt in the last period, i.e. $A_{T}=0$. The interest rates $\left\{r_{t}\right\}_{t=1}^{T}$ are determined by her credit card choice in the first period.

To solve for the optimal consumption, we use the backward induction method. All earlier selves take later selves' actions as an extra constraint, in addition to the budget constraint. Let $V_{\tau}\left(A_{\tau-1}\right)$ be the maximized value of the objective function at period $\tau$ with the beginning asset $A_{\tau-1}$.

$$
V_{\tau}\left(A_{\tau-1}\right)=\max _{C \tau} u\left(C_{\tau}\right)+\beta_{0} \delta \widetilde{V}_{\tau+1}\left(A_{\tau}\right)
$$

The continuation payoff $\widetilde{V}_{\tau+1}\left(A_{\tau}\right)$ is computed from:

$$
\widetilde{V}_{\tau+1}\left(A_{\tau}\right)=u\left(\widehat{C}_{\tau+1}\right)+\delta \widetilde{V}_{\tau+2}\left(\widehat{A}_{\tau+1}\right)
$$

where $\widehat{C}_{\tau+1}$ and $\widehat{A}_{\tau+1}$ are chosen by self $\tau+1$. Since self $\tau$ has no control over self $\tau+1$, she has to take the future self's optimal plan as given. This explains the

\footnotetext{
${ }^{2}$ The complete market assumption is only for exposition purpose. We have relaxed this assumption, where the agent can't save at the credit card rate. The results are similar. This assumption will be further relaxed in the later dynamic model, where the agent faces credit limit and the borrowing and saving rates are not equal.
} 
absence of the ' $m a x$ ' operator in Eq.4.4. The discount factor on $\widetilde{V}_{\tau+2}\left(\widehat{A}_{\tau+1}\right)$ is $\delta$ because the desired discount factor between period $\tau+1$ and period $\tau+2$ is $\delta$ from self $\tau$ 's point of view. $\widehat{C}_{\tau+1}$ and $\widehat{A}_{\tau+1}$ are determined by the following optimization problem where the expected future discount function is used:

$$
V_{\tau+1}^{*}\left(A_{\tau}\right)=\max _{\widehat{C} \tau+1} u\left(\widehat{C}_{\tau+1}\right)+\beta_{1} \delta \widetilde{V}_{\tau+2}\left(\widehat{A}_{\tau+1}\right)
$$

$\widetilde{V}_{\tau+2}\left(\widehat{A}_{\tau+1}\right)$ is used in both Eq.4.4 and Eq.4.5, since self $\tau$ and self $\tau+1$ agree on the expectation about period $\tau+2$ on. This is a special feature of quasi-hyperbolic discounting, which greatly simplifies application.

\section{2 "Rank Reversal"}

As discussed in Chapter 3, "rank reversal" seems to suggest that consumers are time inconsistent. Here we will use the complete information model to demonstrate that the standard exponential model indeed cannot explain it. Only hyperbolic models, where agents are time inconsistent, can rationalize "rank reversal".

Suppose there are two introductory offers $\mathrm{L}\left(r_{L}, \Gamma_{L}\right)$ and $\mathrm{M}\left(r_{M}, \Gamma_{M}\right)$ in the first period, where $r_{i}$ and $\Gamma_{i}$ are the introductory interest rate and duration respectively and $i \in\{L, M\}$, assuming $r_{L}<r_{L}$ and $\Gamma_{M}<\Gamma_{M}$. Offer $\mathrm{L}$ provides a lower introductory interest rate, however, for fewer periods. The representative agent ranks the two credit offers, based on the optimal utility she would receive under each card offer. To simplify the model, there are no more new offers in later periods.

Definition 1: "Rank Reversal" occurs if the optimal utility under offer $L$ is larger than under $M$, however the agent would have paid less interest or received more interest income under $M$, assuming the asset choice under $L$.

Mathematically paying less interest can be formulated as

$$
P D V_{L, M}\left(\left\{A_{t}^{L}\right\}_{t=1}^{T}\right)<P D V_{M, M}\left(\left\{A_{t}^{L}\right\}_{t=1}^{T}\right)
$$


where $\left\{A_{t}^{L}\right\}_{t=1}^{T}$ denotes the optimal debt path under offer $\mathrm{L}$ and

$$
P D V_{j, i}\left(\left\{A_{t}^{L}\right\}_{t=1}^{T}\right)=\sum_{t=1}^{T} \frac{A_{t}^{L}\left(r_{t}^{j}-1\right)}{\prod_{s=1}^{t} r_{s}^{i}}
$$

is the present discounted value of corresponding interest income, where $i, j \in\{L, M\}$.

The "Rank Reversal" essentially means that the agent's preference order in the utility space is different from that in the financial payment space. She prefers the short offer even though she would have paid less interest (received more interest income) for the same debt (asset) path with the longer offer.

Furthermore, if the agent pays less interest under M, the consumption path $\left\{C_{t}^{L}\right\}_{t=1}^{T}$ is also financially feasible under offer $\mathrm{M}$, as shown the Lemma 1 .

\section{Lemma 1:}

$$
\begin{gathered}
P D V_{L, M}\left(\left\{A_{t}^{L}\right\}_{t=1}^{T}\right)<P D V_{M, M}\left(\left\{A_{t}^{L}\right\}_{t=1}^{T}\right) \\
\Rightarrow \sum_{t=1}^{T} \frac{C_{t}^{L}}{\prod_{s=1}^{t-1} r_{s}^{M}}<\sum_{t=1}^{T} \frac{C_{t}^{M}}{\prod_{s=1}^{t-1} r_{s}^{M}}=\sum_{t=1}^{T} \frac{y_{t}}{\prod_{s=1}^{t-1} r_{s}^{M}}+A_{0} .
\end{gathered}
$$

We will use Lemma 1 to prove an important proposition. Proof of Lemma 1 is straightforward, applying Eq. (4.2).

\subsection{1 "Rank Reversal" Impossible for Exponen- tial Agents}

Before prove the proposition, we will first layout two definitions and prove one Lemma.

Definition 2: A game with commitment is one in which self 1 chooses an optimal consumption plan according to her preference, and all later selves are required to follow the plan. Self 1's problem, given an offer $i$, is the following:

$$
\begin{array}{lc} 
& \max _{\left\{C_{\tau}\right\}_{\tau=1}^{T}} u\left(C_{1}\right)+\beta_{0} \sum_{t=2}^{T} \delta^{t-2} u\left(C_{t}\right) \\
\text { s.t. } \quad & \sum_{t=1}^{T} \frac{C_{t}}{\prod_{s=1}^{t-1} r_{s}^{i}}=\sum_{t=1}^{T} \frac{y t}{\prod_{s=1}^{t-1} r_{s}^{i}}
\end{array}
$$


Definition 3: A game without commitment is one in which self $\tau$ chooses her optimal consumption given the initial asset, $A_{\tau-1}$, and she has no control over future selves' choices. The only way she may influence future behavior is by changing the state variable $A_{\tau}$. The problem is defined as:

$$
\begin{array}{cc}
V_{\tau}\left(A_{\tau-1}\right)=\max _{C_{\tau}} u\left(C_{\tau}\right)+\beta_{0} \delta \widetilde{v}_{\tau+1}\left(A_{\tau}\right) \\
\text { s.t. } & C_{\tau}=y_{\tau}-A_{\tau}+r_{\tau-1} A_{\tau-1}
\end{array}
$$

where $\widetilde{v}_{\tau+1}\left(A_{\tau}\right)$ is the expected continuation utility.

The essential difference between the two games is their choice sets. The choice set for the game without commitment is only a subset of that for the game with commitment. The budget constraint is the only constraint in the game with commitment. However, the game without commitment has an additional constraint which is her future behavior. Some financially feasible plan may not be her choice because its implementation issue.

Lemma 2: For an exponential model, solutions are the same for the game with or without commitment.

The lemma is true due to the Principle of Optimality, Bellman (1957). The Principle of Optimality establishes the equivalence between solutions to two problems. The first problem is

$$
\begin{array}{cc}
\max _{\left\{x_{t+1}\right\}_{t=0}^{\infty}} & \sum_{t=0}^{\infty} \delta^{t} F\left(x_{t}, x_{t+1}\right) \\
\text { s.t. } & x_{t+1} \in \Gamma\left(x_{t}\right), t=0,1,2, \ldots \\
& x_{0} \in X \text { given. }
\end{array}
$$

It is easy to see that the consumption game with commitment is a special case of the first problem. The second problem is

$$
v(x)=\max _{y \in \Gamma(x)} F(x, y)+\delta v(y), \text { all } x \in X
$$

The above consumption game without commitment belongs to its class. Therefore Lemma 2 is just a direct application of optimality. 
Proposition: Exponential agents will never exhibit "Rank Reversal".

Proof:

Consumers' credit card usage is best described as a game without commitment defined in Definition 3. For exponential agents, the choice is also optimal for the game with commitment given Lemma 2. Hence the asset path should provide the highest utility among all financially feasible plans. If $P D V_{L, M}\left(\left\{A_{t}^{L}\right\}_{t=1}^{T}\right)<$ $P D V_{M, M}\left(\left\{A_{t}^{L}\right\}_{t=1}^{T}\right)$, the optimal consumption path under $\mathrm{L}$ is also feasible under $M$ as shown in Lemma 1. The optimal choice under $M$ should be better than that under offer L, i.e. offer M should have been chosen instead of L. Therefore, it cannot be the case that $P D V_{L, M}\left(\left\{A_{t}^{L}\right\}_{t=1}^{T}\right)<P D V_{M, M}\left(\left\{A_{t}^{L}\right\}_{t=1}^{T}\right)$ while offer $\mathrm{L}$ is preferred to M.

\subsection{2 "Rank Reversal" Possible for Hyperbolic Agents}

However, the "Rank Reversal" is possible in hyperbolic models. The key reason is that hyperbolic time preference is not consistent. Some consumption plans are not optimal in the future even though they are both financially feasible and preferred in the first period. Therefore, it is possible that the chosen consumption plan which is optimal in every period may incur higher costs than those plans.

We analytically solve the above model, where $T=3$ and $u\left(C_{t}\right)=C_{t}^{1-\rho} /(1-\rho)$. The optimal asset decision is the following:

$$
\begin{aligned}
A_{1} & =\frac{\left(y_{1}+A_{0}\right)-Z\left(y_{3}+r_{2} y_{2}\right)}{1+r_{1} r_{2} Z}, \\
A_{2}^{\exp } & =\frac{y_{2}+r_{1} A_{1}-\left(\beta_{1} \delta r_{2}\right)^{-\frac{1}{\rho}} y_{3}}{1+\left(\beta_{1} \delta r_{2}\right)^{-\frac{1}{\rho}} r_{2}}, \\
A_{2}^{\text {real }} & =\frac{y_{2}+r_{1} A_{1}-\left(\beta_{0} \delta r_{2}\right)^{-\frac{1}{\rho}} y_{3}}{1+\left(\beta_{0} \delta r_{2}\right)^{-\frac{1}{\rho}} r_{2}},
\end{aligned}
$$

in which

$$
Z=\left[\beta_{0} \delta r_{1} r_{2}\left(\frac{X}{1+X r_{2}}\right)^{1-\rho}+\beta_{0} \delta^{2} r_{1} r_{2}\left(\frac{1}{1+X r_{2}}\right)^{1-\rho}\right]^{-1 / \rho}
$$


where $X=\left(\beta_{1} \delta r_{2}\right)^{-\frac{1}{\rho}} . A_{2}^{\exp }$ is the expected behavior of self 2 from self 1 's point of view and $A_{2}^{\text {real }}$ is the real behavior of self 2 . The two are the same in the sophisticated hyperbolic model, where $\beta_{0}=\beta_{1}$. Given $A_{1}, A_{2}^{\text {real }} \leq A_{2}^{\exp }$, since $d F / d \beta>0{ }^{3}$ and $\beta_{1} \geq \beta_{0}$, where

$$
F=\frac{y_{2}+r_{1} A_{1}-\left(\beta \delta r_{2}\right)^{-\frac{1}{\rho}} y_{3}}{1+\left(\beta \delta r_{2}\right)^{-\frac{1}{\rho}} r_{2}}
$$

In another words, self 1 underestimate (overestimate) her debt (saving) at period 1 when the inequality is true.

Given all other parameters, does a naive hyperbolic agent borrow more than a sophisticated consumer in the first period? Intuitively the naive agent should borrow more since she doesn't expect herself to borrow so much in the second period. On the other hand, the sophisticated consumer should accommodate future overspending by borrow less at the first period. Actually the answer depends on $\rho$. When $\rho<1$, $d A_{1} / d \beta_{1}>0$, i.e. the naive consumer saves more. When $\rho>1, d A_{1} / d \beta_{1}<0$, i.e. the naive consumer borrows more. When $\rho=1$, they behave the same. The intuition is that when $\rho>1$ the agent really would like to spread consumption over time. Therefore a sophisticated self 1 would like to borrow less to accommodate her borrowing in the second period. However when $\rho<1$ the self 1 doesn't care much about smoothing consumption. If she knows that self 2 will spend too much, she would leave less wealth to self 2 . The mathematical proof is in the Appendix.

Another interesting finding from the above analytic solutions is that the naive model behaves observationally similar to the sophisticated model when the present bias is small $\left(\beta_{0} \rightarrow 1\right)$. The difference between the two models explodes when $\beta_{0} \rightarrow 0$. Given $A_{1}$, both naive and sophisticated agents will borrow (save) according to $A_{2}^{\text {real }}$. The difference in $A_{1}$ is from $Z . d Z / d \beta_{1}$ is a function of $\left(\beta_{0}\right)^{-1 / \rho}$. When $\beta_{0} \rightarrow 0,\left(\beta_{0}\right)^{-1 / \rho} \rightarrow \infty$, since $\rho>0$. Therefore $d Z / d \beta_{1} \rightarrow \infty$ and $d A_{1} / d \beta_{1} \rightarrow \infty$. On the other hand, when $\beta_{0} \rightarrow 1$, so is $\beta_{1}$ since $\beta_{1} \geq \beta_{0}$. $d Z / d \beta_{1}$ is a function of $\left(\beta_{1}-1\right)$. Therefore $d Z / d \beta_{1} \rightarrow 0$ as $\left(\beta_{1}-1\right) \rightarrow 0$.

\footnotetext{
${ }^{3}$ All derivatives are evaluated in Appendix.
} 
We will use numerical examples to illustrate some other interesting findings, which are not easy to see from the analytic solution. Assume $\rho=2, y_{1}=y_{2}=y_{3}=1$ and $A_{0}=0$. Offer L carries an interest rate of $5 \%$ for the first period and $20 \%$ for the second period. Offer $\mathrm{M}$ has a flat interest rate schedule: $10 \%$ for both periods. Fig.(4.2) plots the rank reversal region (the shaded area) in $\beta$ and $\delta$ space, for sophisticated and naive models. For both models there are only two preference parameters. For the sophisticated agent $\beta_{1}=\beta_{0}=\beta$. The naive agent has a $\beta_{1}=1$, $\beta_{0}=\beta$. Apparently, there is no rank reversal when $\beta=1$, which is the exponential model. However, there exists a wide rank reversal area for hyperbolic models.

A naive agent exhibits "rank reversal" because she underestimates her future borrowing. For example, suppose $\beta=0.82$ and $\delta=1$. In the first period, she prefers offer L because she expects that $A_{1}=-0.0207$ and $A_{2}^{\exp }=0.0312$. However, when the second period arrives she gives in to her instantaneous desire and borrows again, $A_{2}^{\text {real }}=-0.0135$. Base on her actual behavior, she has made a suboptimal choice in the first period. However, her decision is optimal based on her expectation.

A sophisticated agent does not behave suboptimally because of incorrect expectations, rather because she tries to align her future behavior with her current preference. Continue to suppose $\beta=0.82$ and $\delta=1$. If she can commit to her future behavior, she will choose $A_{1}=-0.0207$ and $A_{2}=0.0312$. However, she anticipates that this plan will not be followed in the second period. Still she decides to borrow less in period one $\left(A_{1}=-0.0199\right)$ to accommodate tomorrow's borrowing $\left(A_{2}=-0.0131\right)$. Based on her reduced first-period debt, the interest payment under $\mathrm{L}$ is more than M. However it is not optimal to choose M since this consumption plan will not be implementable if $\mathrm{M}$ is chosen. Given $A_{1}=-0.0199$, she will borrow much more under offer $\mathrm{M}$ in the second period $\left(A_{2}=-0.0347\right)$, which is worse from her first period's point of view.

Given any $\delta$, a smaller $\beta$ will be more likely in the rank reversal region. As the difference between the long term desired discount factor $(\delta)$ and the short term 


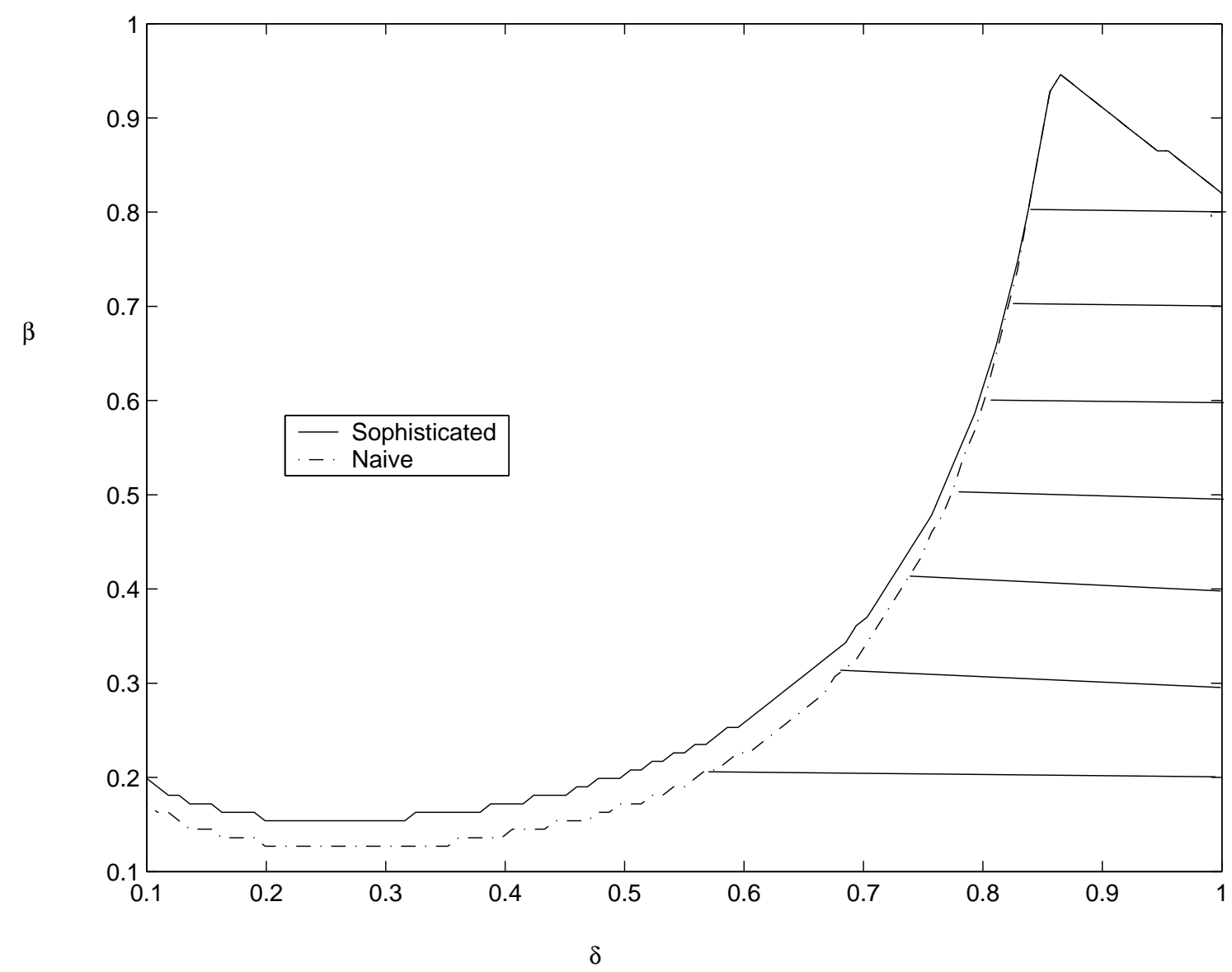

Figure 4.2: Rank reverse area of Sophisticated and Naive Hyperbolic Agents 
temptation $(\beta \delta)$ becomes larger, an naive agent's underestimation error is larger and more desperate the sophisticated agent wants to constrain herself. Both will lead to financially suboptimal behavior.

Only when $\beta$ is really small, less than 0.8 in this numerical example, rank reversal region for sophisticated agents separates from that of naive agents. The same is true for asset choices. As shown above, whether the agent recognizes selfcontrol problem or not makes a behavioral difference only when the self-control problem is severe. As $\beta \rightarrow 1$, both models converge to the exponential model. 


\section{Chapter 5}

\section{A Multi-period Incomplete Information Model}

A dynamic model, which captures consumer decision problem in the market experiment more realistically, is presented in this chapter. Compared with the previous model, this dynamic model has four realistic institution features. First, consumers face uninsurable income risk, both transitory and persistent income shocks. Second, consumers receive new introductory offers from other credit card companies every period. Third, receiving new offers is an probabilistic event. Consumers have a rational assessment of what is the probability of new offers. Fourth, consumers have a time varying switching cost every period. This captures different perceived costs involved in switching. The difference may due to the variance of consumers' personal time schedule or the variance of their emotional status.

All realistic features are added to explore the possibility of explaining "rank reversal" by random shocks. Consumers' preference for the short offer A may be optimal based on their expectation about future, though not according to the true realization. For example some consumers may have chosen the short offer under the expectation that they will switch out after six months. However, they fail to transfer because they are too busy. 


\subsection{Model Setup}

The model is inspired by standard "buffer-stock" life-cycle models, Carroll (1992, 1997a), and Deaton (1991). This model is set in discrete time. One period in the model represents one quarter in the real world. The consumer lives for $T$ periods. The boundary condition is that the consumer consumes all her cash-on-hand at the final period. ${ }^{1}$ The consumer receives stochastic income every period. She can either save in her saving account or borrow on credit cards to smooth her consumption. However, she is liquidity constrained in two aspects. First, she is restricted in her ability to borrow. The upper bound is the total credit limit of her credit cards, denoted as $\bar{L}$, which is exogenously given. However nothing prevents her from accumulating liquid assets. Second, she faces different interest rates depending on whether she is savings $\left(r^{s}\right)$ or borrowing $(r)$, where $r>r^{s}$, and $r$ is the regular interest rate on credit cards.

The consumer can reduce the interest payment on her debt if she accepts an introductory offer. At the beginning of period 1, the credit card company that conducted this market experiment, denoted as Red, offers the consumer an introductory interest rate $r^{r}<r$ with a duration $\tau^{r}$ periods, and a credit limit $l$. The consumer may also receive credit card solicitations from other credit card companies which are not observed in this dataset. These unobservable companies are simplified as one company, Blue. Blue provides an introductory interest rate $r^{b}<r$ with an introductory duration of $\tau^{b}$ and a credit limit also $l$. The consumer's total credit limit $\bar{L}$ is held constant even after accepting a new offer to simplify computation. This is an innocuous assumption since respondents have so much unused credit limit: the average debt is only $\$ 2,000$ while the average credit limit is $\$ 6,000$ on this observed card and $\$ 15,000$ on other cards. In every period, the consumer receives a Blue offer

\footnotetext{
${ }^{1}$ The model is chosen to have finite horizon because the standard contraction map theory fails for sophisticated hyperbolic models. See Laibson $(1997,1998)$ and for more details. We choose $T$ large enough, so that results will not be sensitive to it.
} 
with a probability $q$, which is positive and finite if the consumer has no existing introductory offer from Blue, otherwise zero. ${ }^{2}$

Simultaneously with the acceptance of credit card offer(s), the consumer decides how much to consume at the beginning of period $t$. There is a switching cost, $k_{t}$, associated with accepting every introductory offer. The switching cost is indexed by $t$ because it is assumed that the consumer has a time-varying switching cost. This assumption is required because respondents with similar credit card debt fail to switch after this red offer expires. Simulation results show that respondents will definitely switch again after the offer expires if the following three conditions hold. The first is that their credit card debt remains the same. Second, they have fixed switching costs. Third, there are new offers available. This is true for both hyperbolic and exponential agents. As mentioned before, respondents must have some other offers available, since their credit status is good and there are numerous credit card solicitations in the sample period. The only possible explanation is that consumer switching costs are changing over time. Respondents of this experiment accepted the offers due to their low realized switching costs at the time of solicitation. However, their mean switching costs are much higher, which can be partially inferred from the low response rate (1\%). This high mean will keep the majority of respondents from switching a second time after the introductory periods. The switching cost captures the (expected) time and effort required in filling out an application for a new card. It is assumed that there is no extra cost for transferring balance after the consumer accepts a new offer. Once she accepts introductory offer(s), she has immediate access to the credit.

The consumer in period $t$ maximizes a weighted sum of utilities from current

\footnotetext{
${ }^{2}$ This assumption effectively excludes that consumers have more than one introductory offer from Blue. We believe relaxing it will only complicate the problem with little benefit.
} 
period on which is summarized in the following Eq.(5.1).

$$
\begin{array}{ll}
V_{t, t}\left(\Lambda_{t}\right)=\max _{C_{t}, d_{t}^{b}, d_{t}^{r}} \frac{C_{t}^{1-\rho}}{1-\rho}-d_{t}^{b} k_{t}-d_{t}^{r} k_{t}+\beta_{0} \delta E\left\{\widetilde{V}_{t, t+1}\left(\Lambda_{t+1}\right)\right\}, & \text { for } t=1, \\
V_{t, t}\left(\Lambda_{t}\right)=\max _{C_{t}, d_{t}^{b}} \frac{C_{t}^{1-\rho}}{1-\rho}-d_{t}^{b} k_{t}+\beta_{0} \delta E\left\{\widetilde{V}_{t, t+1}\left(\Lambda_{t+1}\right)\right\}, & \text { for } t \geq 2 .
\end{array}
$$

Eq.(5.1) is similar to Eq.(4.3) in the previous section. The instantaneous utility is the sum of the consumption utility and the disutility (the switching cost) from accepting an introductory offer. $C_{t}$ and $d_{t}^{b}$ are the consumption choice and the decision to accept an introductory offer from Blue at period t respectively. $d_{1}^{r}$ is the decision to accept the Red offer at period $1 . k_{t}$ is the current switching cost. The consumption function is assumed to be CRRA and $\rho$ is the coefficient of relative risk aversion. $\Lambda_{t+1}$ denotes the vector of state variables: $\left\{X_{t+1}, \varphi_{t+1}, k_{t+1}, \tau_{t+1}^{b}, \Gamma_{t+1}^{r}, s_{t+1}\right\} . X_{t+1}$ is cash-on-hand at the beginning of period $t+1$, which is a sum of stochastic income, $y_{t+1}$, and wealth, $A_{t+1} \cdot \varphi_{t+1}$ is the realized persistent income shock at period $\mathrm{t}+1$, which will be discussed in more detail later. $k_{t+1}$ is the realized switching cost in period $\mathrm{t}+1 . \tau_{t+1}^{b}$ and $\Gamma_{t+1}^{r}$ denote the number of introductory periods left on the Blue and Red card at period $t+1$ respectively. $s_{t+1}$ denotes whether a new introductory offer is received at period $t+1$. The expectation is taken with respect to the distributions of $y_{t+1}, \varphi_{t+1}, k_{t+1}$ and $s_{t+1}$.

$\widetilde{V}_{t, t+1}$ is a weighted sum of self $t^{\prime}$ s excepted future utilities and it is recursively defined as:

$$
\widetilde{V}_{t, t+1}\left(\Lambda_{t+1}\right)=\frac{\widehat{C}_{t+1}^{1-\rho}}{1-\rho}-\widehat{d}_{t+1}^{b} k_{t+1}+\delta E\left\{\widetilde{V}_{t+1, t+2}\right\}
$$

$\widetilde{C}_{t+1}$ and $\widetilde{d}_{t+1}^{b}$ are the behavior of the expected self $t+1$. Self $t$ take the expected self $t+1$ 's behavior as given so that there is not ' $\max ^{\prime}$ operator in Eq.5.2. The discount factor between period $t$ and $t+1$ is $\delta$ because the relative discount factor from self $t$ 's point of view is $\beta \delta^{2} / \beta \delta=\delta$. $\widetilde{V}_{t+1, t+2}$ is used instead of $\widetilde{V}_{t, t+2}$ because they are the same. Self $t$ and self $t+1$ have the same expectation about periods later than $t+1$. This special feature of quasi-hyperbolic models makes it easier to compute. $\widehat{C}_{\tau+1}$ and $\widehat{d}_{\tau+1}^{b}$ are determined by the following optimization problem where 
the expected future discount function is used:

$$
V_{\tau+1}^{*}\left(A_{\tau}\right)=\max _{\widehat{C} \tau+1, \widehat{d}_{\tau+1}^{b}} \frac{\widehat{C}_{t+1}^{1-\rho}}{1-\rho}-\widehat{d}_{\tau+1}^{b} k_{t+1}+\beta_{1} \delta E\left\{\widetilde{V}_{t+1, t+2}\left(\Lambda_{t+1}\right)\right\}
$$

This consumer problem is solved numerically by backward induction. Iterate Eq.(5.3) and Eq.(5.2) to generate the expected continuation utility function $\widetilde{V}_{t, t+1}$. Combine the $\widetilde{V}_{t, t+1}$ and Eq.(5.1) to calculate decision rules, $C_{\tau}, d_{1}^{r}$ and $d_{\tau}^{b}$.

\subsection{Numerical Simulation and Model Pre- diction}

In this section we use some numerical simulations to provide intuition about the model behavior. The same simulation strategy applies to estimate related parameters in next chapter. In order to simulate the model we calibrate a subset of parameters, such as the income process, outside credit card offers. The calibration choices are discussed in details at the next section.

It is a well-documented observation that sophisticated hyperbolic models have irregular policy functions as the short-term discount factor, $\beta$, becomes smaller. (Krusell and Smith 2000, Harris and Laibson 2001a). The irregularity is due to strategic actions between selves at different periods. Due to time inconsistent preference, an early self desires different actions from a later self than what the later self will actually behave. Therefore, the early self will behave strategically, trying to align the later self's behavior as close as possible to what her wish is.

Fig.(5.1) plots the asset choice $A_{t+1}$ as a function of cash-on-hand at period $t$, $X_{t}$, for different $\beta_{\mathrm{s}}$. The left graph is for the naive hyperbolic model and the right is for the sophisticated hyperbolic model. The asset function of the naive model is regular for all $\beta$ values, since naive agents don't recognize time inconsistency. However when $\beta=0.5$, the asset function of the sophisticated model is a step function, which is quite irregular. If converting asset functions into consumption functions, the 

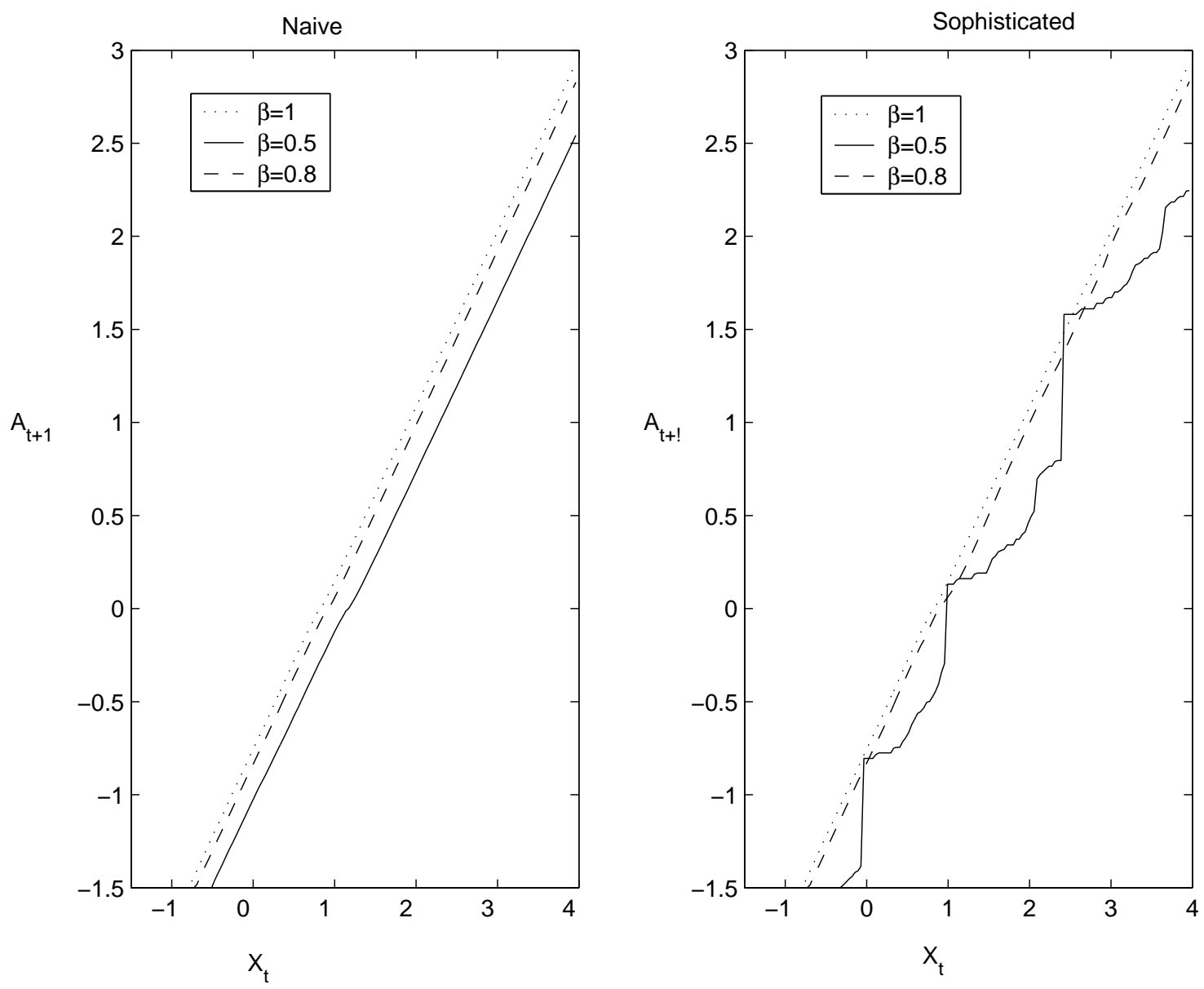

Figure 5.1: Policy functions. The asset choice $A_{t+1}$ is a function of cash-on-hand at period $t, X_{t}$, for different $\beta$ s. 


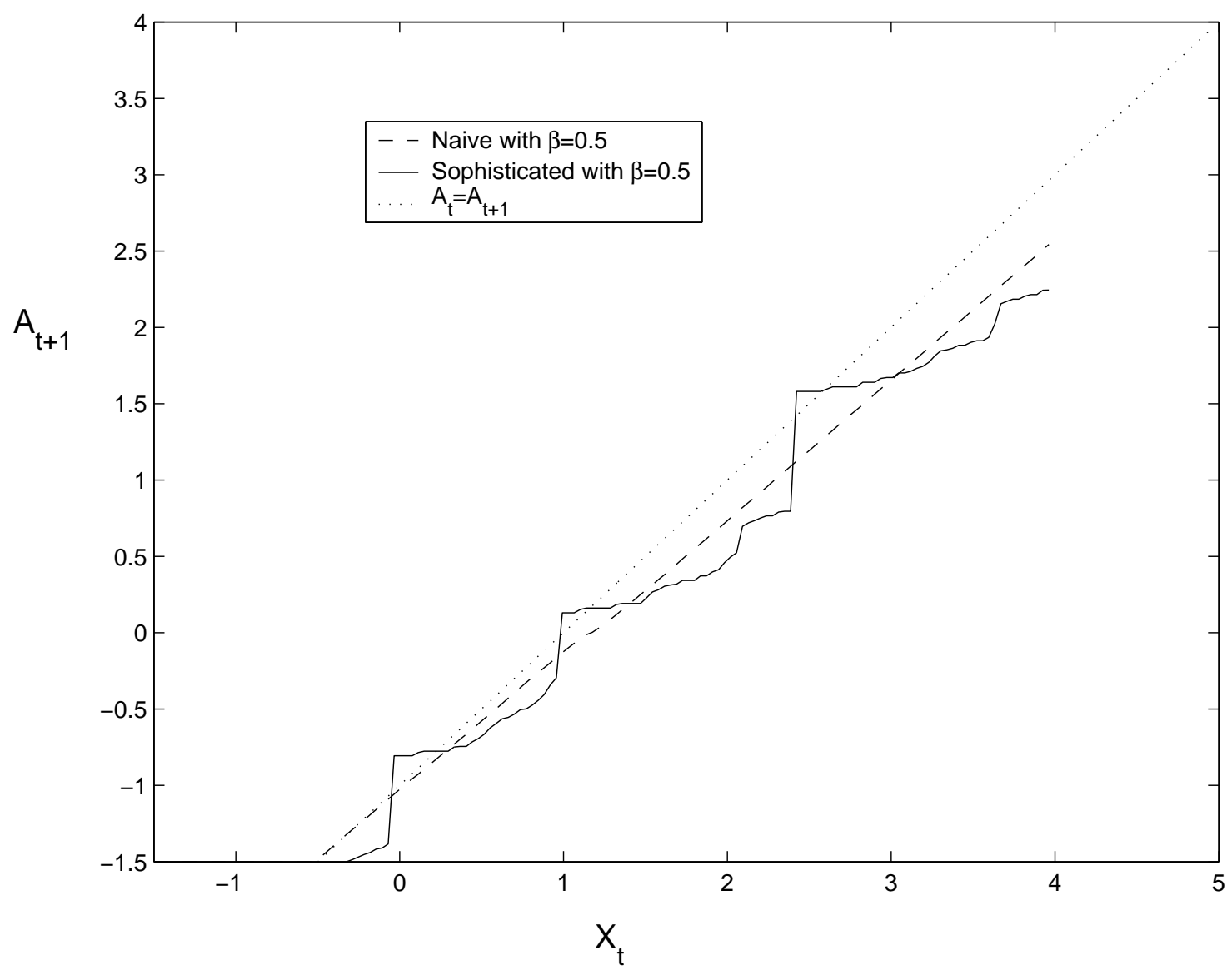

Figure 5.2: Policy functions. The asset choice $A_{t+1}$ is a function of cash-on-hand at period $t, X_{t}$, when $\beta=0.5$. 
regular asset function corresponds to a concave, monotonic consumption function. However the step function will generate a non-monotonic consumption function. When $\beta$ is close to 1 , the asset functions for the naive model are similar to those for the sophisticated model, consistent with our finding in the complete information model. When $\beta=0.5$, the two models behave qualitatively different. However, they have a similar mean. The sophisticated asset function varies around the naive one which is shown in Fig.(5.2).

Can random shocks explain "Rank Reversal"? Simulation results reveal that the conflict between preference for the short offer A and later low switching is still inexplicable in the exponential model. In the top panel of Table (5.1), exponential agents' response to offer $\mathrm{A}$ and $\mathrm{F}$ are reported for different discount factors $\delta$, given other parameters. The more patient the agents are, the higher response rate to the short offer A compared with that to offer F. Patient consumers expect that their debt will be short-lived so that the shorter offer A is better. On the contrary, agents are more likely to accept the longer offer when they become impatient. At the same time, impatient respondents will be more likely to stay with the card after the interest rate jumps to $16 \%$. The corresponding average debt for borrowers in Market Cell A are shown in Fig.(5.3). The time consistent agents always prefer an offer incurring the least cost. The short offer costs less only if the debt declines rapidly over time. Under that scenario, earlier interest saving can compensate for the later higher interest rate. Therefore there doesn't exit a $\delta$, which can simultaneously explain the two phenomena.

However, there exists $\beta$ such that both sophisticated and naive models predict that agents prefer the short offer and they keep on borrowing on the card for a long period. Simulation results for the sophisticated and naive are reported in Table (5.1), Fig.(5.4) and Fig.(5.5), where $\beta$ adopts different values and $\delta$ is assumed to be fixed. When $\beta$ is very low, like 0.7 , the longer offer is preferred by the sophisticated hyperbolic agent because it saves much more interest than the short one, which 


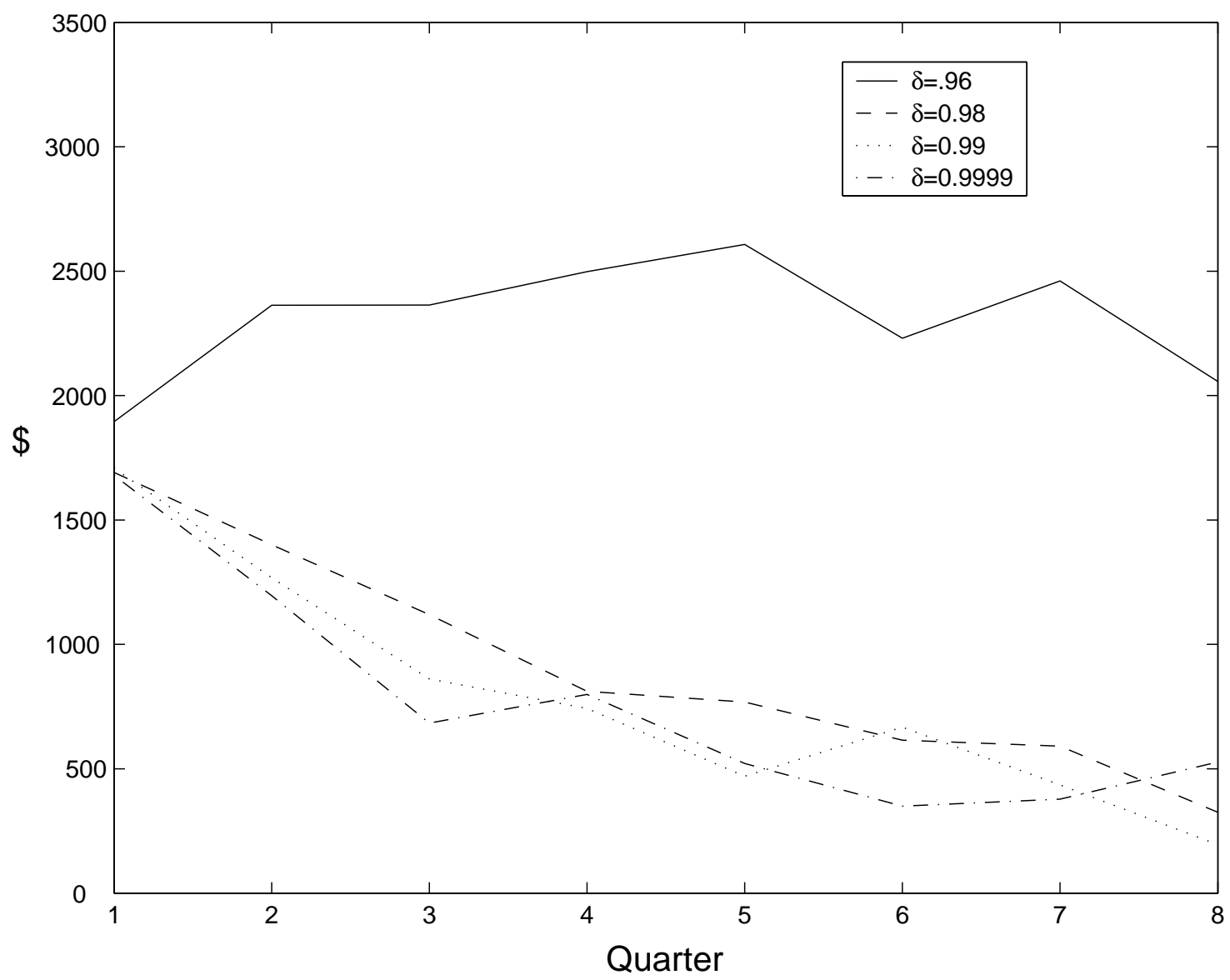

Figure 5.3: Simulated mean debt among borrowers in market cell A for the exponential model. 


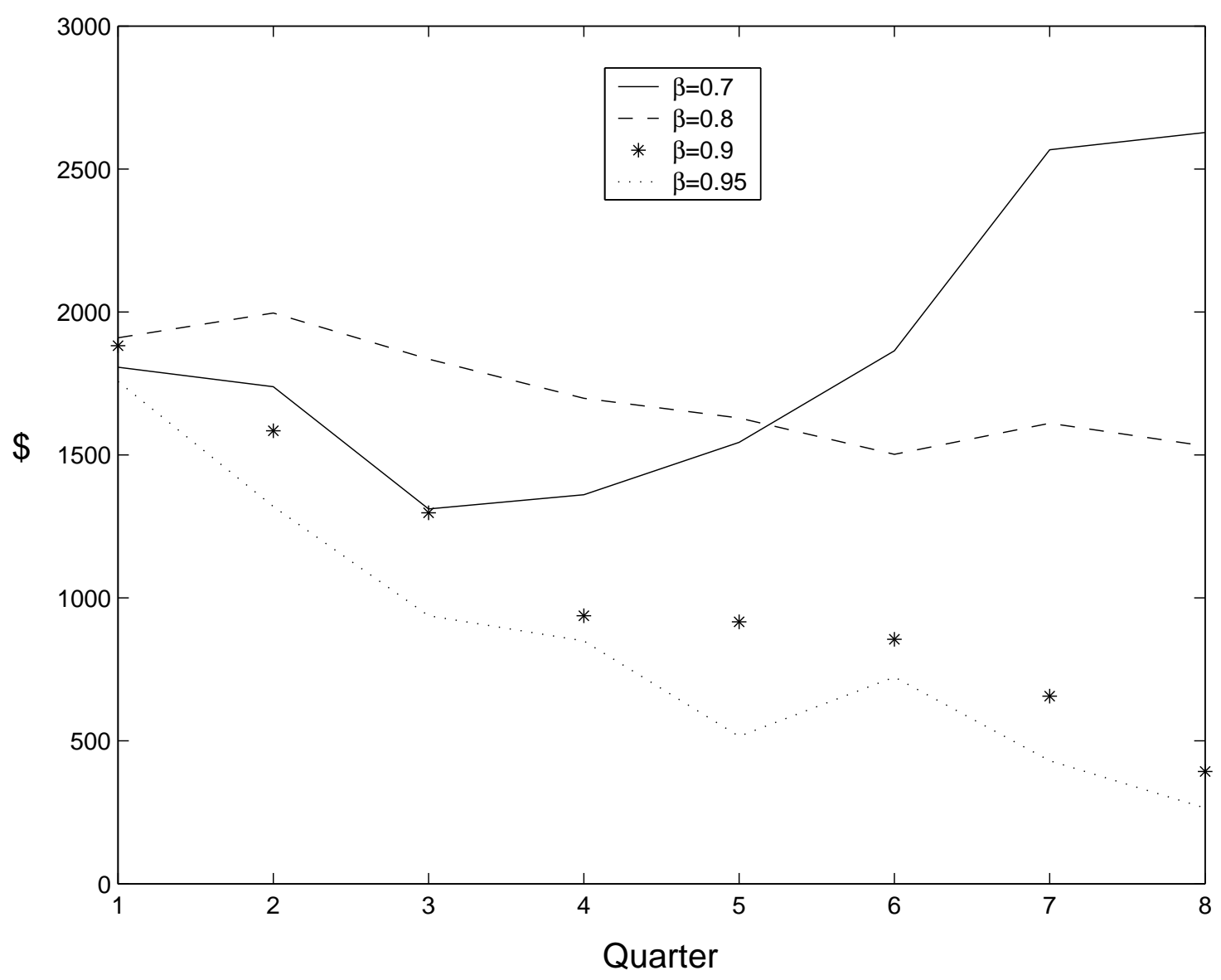

Figure 5.4: Simulated mean debt among borrowers in market cell A for the sophisticated hyperbolic model. 




Figure 5.5: Simulated mean debt among borrowers in market cell A for the naive hyperbolic model. This is the actual borrowing not expected. 


\begin{tabular}{|c|c|c|c|c|}
\hline Exponential & & & & \\
\hline$\delta$ & 0.96 & 0.98 & 0.99 & 0.9999 \\
\hline $\mathrm{A}$ & 152 & 72 & 53 & 41 \\
$\mathrm{~F}$ & 476 & 100 & 71 & 36 \\
\hline Sophisticated & & & & \\
\hline$\beta$ & 0.7 & 0.8 & 0.9 & 0.95 \\
\hline $\mathrm{A}$ & 98 & 80 & 54 & 47 \\
$\mathrm{~F}$ & 133 & 72 & 41 & 49 \\
\hline Naive & & & & \\
\hline$\beta$ & 0.7 & 0.8 & 0.9 & 0.95 \\
\hline A & 133 & 90 & 59 & 47 \\
$\mathrm{~F}$ & 127 & 91 & 57 & 45 \\
\hline
\end{tabular}

Table 5.1: Response rates for different time preferences. Response is based on 10,000 simulations. $\beta, \delta$ are discount factors. $\delta=0.9999$ for both hyperbolic models. Other parameters are assumed to be the the same for all three models. $k$, the switching cost parameter, is assumed to be 0.03 . Mean of $A_{1}$ is 5000 and variance is $8 \mathrm{e} 6$, which is liquid assets at the time of solicitation. 
outweighs the benefit of constraining future selves. However, when $\beta$ is moderate, like 0.8 , the sophisticated hyperbolic agent would like the short offer which will save them money in the near future and constrain them to borrow less in the future. On the other hand, the naive hyperbolic agent always respond more to the short offer even when $\beta=0.7$. She doesn't plan to borrow after current period because her desired discount rate $\delta=0.9999$ in this simulation. Fig.(5.5) plots the actual borrowing for the naive agent, not her plan. The simulated debt path for $\beta=0.8$ is qualitatively the same as what is observed in the experiment for both hyperbolic models. Only when $\beta=0.7$, the naive model behaves significantly different from the sophisticated model. This is due to their different policy functions as discussed above. 


\section{Chapter 6}

\section{Estimation}

In this chapter, we will apply the dynamic model to the empirical data and estimate related parameters.

\subsection{Estimation Strategy}

To estimate the above dynamic model by using Maximum Likelihood method, the objective function involved is too complicated to compute. There is endogenous sampling at the first period: only $1 \%$ accepted the credit card solicitation and we only observe respondents' subsequent borrowing behavior. To account for this endogeneity, the likelihood function will involve high dimensional integration which is computational prohibitive. To circumvent this problem, the parameters of the model are estimated by matching empirical moments with simulated moments from the dynamic model. The estimation method used is Simulated Minimum Distance Estimator (SMD), proposed in Hall and Rust (2002). ${ }^{1}$ This method accounts for the endogenous selection with the least computation cost.

The SMD estimator is the parameter value $\theta$ which minimizes the distance

\footnotetext{
${ }^{1}$ This method is similar to Simulated Moments Estimator (SME) of McFadden (1989) and Pakes and Pollard (1989).
} 
between a set of simulated and sample moments. The sample moments are calculated based on censored observations, respondents. Consumer behavior for a given trial value $\theta$ is simulated and similar moments are calculated based on simulated respondents, who are censored in exactly the same way as the empirical data. Even though various moments based on censored data may be biased, the SMD estimator is consistent as proved in Hall and Rust (2002).

Denote the empirical moments we want to match as

$$
h\left(\theta^{*}\right)=\sum_{i=1}^{N} \frac{1}{N} h_{i}\left(\theta^{*}\right)
$$

which is the mean among the sample and $\theta^{*}$ is the underlying true parameters. The simulated moments is a function of the parameter vector $\theta$, as

$$
h(\theta)=\sum_{i=1}^{N} \frac{1}{N} h_{i}(\theta)
$$

The simulated minimum distance estimator $\widehat{\theta}$ is defined by:

$$
\widehat{\theta}=\arg \min _{\theta \in \Theta}\left(h(\theta)-h\left(\theta^{*}\right)\right)^{\prime} W\left(h(\theta)-h\left(\theta^{*}\right)\right)
$$

In this study, total 216 moments are used, 36 for each market cell. The 36 moments are the response rate plus five debt distribution statistics for seven quarters: proportion of consumers who borrow, mean, median, forty and sixty percentiles among borrowers. The debt statistics for the first quarter is omitted because they underestimates respondents' debt. This underestimation is because it takes about 2-3 months for respondents to accumulate debt on this card. This time lag is not modeled in the dynamic model.

Hall and Rust (2002) proves that the optimal weighting matrix $W^{*}$ is

$$
W^{*}=\left(\Omega\left(h\left(\theta^{*}\right)\right)\right)^{-1}, \text { where } \Omega\left(h\left(\theta^{*}\right)\right)=\frac{1}{N} \sum_{i=1}^{N}\left(h_{i}\left(\theta^{*}\right)-h\left(\theta^{*}\right)\right)\left(h_{i}\left(\theta^{*}\right)-h\left(\theta^{*}\right)\right)^{\prime}
$$

The problem with the optimal weighting matrix is that it doesn't give enough weight to the response rates. Among the total 216 moments only 6 moments are response 
rates so that the relative weight on debt path is much larger than on response rates. This is not reasonable because the response rates directly reveal preferences of the full sample. The debt path only conveys information about $1 \%$ of the sample. The correct weighting matrix should put a much larger weight on the response rates. Hence, we create our weighting matrix which puts $80 \%$ weight on response rates and $20 \%$ on debt path. Among six market cells, $1 / 3$ is on cell A, $1 / 3$ is on $\mathrm{F}$ and the remaining $1 / 3$ is equally distributed among $\mathrm{B}, \mathrm{C}, \mathrm{D}, \mathrm{E}$.

The asymptotic distribution of estimated $\widehat{\theta}$ is

$$
\sqrt{N}\left(\widehat{\theta}-\theta^{*}\right) \rightarrow N\left(0,2 \Lambda_{1}^{-1} \Lambda_{2} \Lambda_{1}^{-1}\right)
$$

where

$$
\begin{aligned}
& \Lambda_{1}=\nabla \operatorname{Eh}\left(\theta^{*}\right)^{\prime} \cdot W \cdot \nabla \operatorname{Eh}\left(\theta^{*}\right) \\
& \Lambda_{2}=\nabla \operatorname{Eh}\left(\theta^{*}\right)^{\prime} W \cdot \Omega\left(h\left(\theta^{*}\right)\right) \cdot W \cdot \nabla \operatorname{Eh}\left(\theta^{*}\right)
\end{aligned}
$$

$W$ is the weighting matrix, $\Omega\left(h\left(\theta^{*}\right)\right)$ is the variance matrix of the moments, and $\nabla E h\left(\theta^{*}\right)=\frac{\partial E h\left(\theta^{*}\right)}{\partial \theta^{*}}$. The factor 2 is to account for simulation error. If analytic model moments are used a factor of 1 should be used instead.

The over-identification $\chi^{2}$ statistics is:

$$
\frac{T}{2}\left(h(\widehat{\theta})-h\left(\theta^{*}\right)\right)^{\prime} P^{-1}\left(h(\widehat{\theta})-h\left(\theta^{*}\right)\right)
$$

where

$P=\left[I-\nabla E h\left(\theta^{*}\right) \Lambda_{1}^{-1} \nabla E h\left(\theta^{*}\right)^{\prime} \cdot W\right] \cdot \Omega\left(h\left(\theta^{*}\right)\right) \cdot\left[I-\nabla E h\left(\theta^{*}\right) \Lambda_{1}^{-1} \nabla E h\left(\theta^{*}\right)^{\prime} \cdot W\right]$.

To make estimation feasible, we calibrate a subset of parameters, using related literature and our dataset, and make assumptions about exogenous variables' distributions. First is the income process, which is modeled as a time series with changes in two possible states: a good state and a bad state. The persistent income shock is captured by a two-state Markov process, $\varphi_{t} \in\{1,0\}$, where 1 and 0 represent the good and bad state respectively. The method was introduced in Laibson et al. 
(2000) which significantly reduces the computational cost. The transition probabilities between the two states is governed by the conditional probabilities matrix: $\left\{p_{i, j}\right\}$, where $i, j \in\{1,0\}, p_{i, j}=\operatorname{prob}\left(\varphi_{t}=i / \varphi_{t-1}=j\right)$. In a given state, income is a random draw from a lognormal distribution, $L N\left(\eta^{j}, \varepsilon^{j}\right)$, where $j \in\{g, b\}$. The lognormal distribution captures the transitory income shock. Its distribution parameters depend on whether it is in the good state or the bad state. To get reasonable estimates for the income distribution, we use estimates from Laibson et al. (2000) as a starting point. We describe the detailed calibration of income process in Appendix.

We assume consumer switching cost, $k_{t}$, is an identical and independent random draw from a uniform distribution with a range $[0, k]$. We assume, at the time of solicitation, consumer liquid asset/credit card debt follows a normal distribution with a mean of $\mu$ and a variance of $\epsilon^{2}$.

We calibrate the total credit limit, $\bar{L}$, and the credit limit for each credit card (recall that they are assumed the same), $l$, using the information in the dataset. The calibrated $\bar{L}$ are $\$ 15,000$ and $l$ is $\$ 6,000$. In addition, the regular interest rate for credit cards $r$ is assumed to be $1.16 \%$, and the saving interest rate $r_{s}=1.01 \%$. The relative risk aversion coefficient $\rho$ is assumed to be 2 .

The introductory interest rates and durations of the Red offers, $r_{r}$ and $\tau_{r}$ are given in the experiment dataset. However, we don't observe introductory offers consumers received in subsequent periods. We assume the duration for the Blue offer is 6 months, which is the typical duration in the company we observed. The interest rate on the Blue offer is assumed to be $8 \%$.

We assume consumers have a probability of $90 \%$ to receive Blue offers. As argued before, we believe respondents should receive new offers every quarter with a probability of almost one in the sample period. It is assumed $1 \%$ consumers have an ongoing Blue offer at the time of the Red solicitation which was the average response rate to credit card solicitations at the sample period. 
Given the calibrated parameters and the distribution assumptions, we estimate remaining parameters by SMD. The estimated parameters are the time discount factors, $\beta$ and $\delta$, the switch cost distribution parameter $k$, and the parameters of the liquid asset distribution at the beginning of period 1 , the mean $\mu$ and the variance $\epsilon^{2}$. We estimate parameters for three models: exponential, naive and sophisticated hyperbolic. For the exponential model, $\beta=1$. For the naive model, $\beta_{1}=1$ and $\beta_{0}=\beta$ is estimated. For the sophisticated model, $\beta_{1}=\beta_{0}=\beta$. Their standard errors are calculated according to Eq.(6.1).

\subsection{Estimation Results}

Estimation results for the dynamic model are reported in Table (6.1). "Goodnessof-Fit" is the weighted distance between empirical moments and simulated moments. Allowing for hyperbolic time preferences significantly improves fit, reducing the distance by more than half. As explained in the previous chapter, the failure of exponential discounting is expected because the exponential model cannot simultaneously explain consumer response to different offers and respondents' later borrowing behavior. Even after random shocks are incorporated into the model, time consistent consumers on average exhibit consistent behavior. Only by allowing consumers to have time inconsistent preferences, can the model prediction match the empirical data.

An inspection of Table (6.1) shows that all parameters are estimated precisely. The parameters for both hyperbolic models are very close, while those of the exponential model are quite different. As shown in the previous chapter, the sophisticated model is similar as the naive model when $\beta$ is close to 1 . There is only a small quantitative difference: given $\beta$ and $\delta$, naive consumers borrow more and are more eager to accept new offers. Therefore, the naive model needs a larger $\beta$ to match the consumer debt level and a larger switching cost to keep consumers 


\begin{tabular}{|c|c|c|c|}
\hline & $\begin{array}{c}\text { Sophisticated } \\
\text { Hyperbolic }\end{array}$ & $\begin{array}{c}\text { Naive } \\
\text { Hyperbolic }\end{array}$ & Exponential \\
\hline$\beta$ & $\begin{array}{c}0.7863 \\
(0.00192)\end{array}$ & $\begin{array}{c}0.8172 \\
(0.003)\end{array}$ & \\
\hline$\delta$ & 0.9999 & 0.9999 & 0.9999 \\
& $(0.00201)$ & $(0.0017)$ & $(0.00272)$ \\
\hline$k$ & 0.02927 & 0.0326 & 0.1722 \\
& $\$ 293$ & $\$ 326$ & $\$ 1,722$ \\
& $(0.00127)$ & $(0.00139)$ & $(0.0155)$ \\
\hline$\mu$ & 1.0088 & 0.9584 & 1.5836 \\
& $\$ 5,044$ & $\$ 4,792$ & $\$ 7,918$ \\
& $(0.0367)$ & $(0.0277)$ & $(0.0517)$ \\
\hline$\epsilon^{2}$ & 0.831 & 0.8167 & 4.278 \\
& $\$ 8,310,000$ & $\$ 8,167,000$ & $\$ 42,780,000$ \\
& $(0.0439)$ & $(0.0373)$ & $(0.0535)$ \\
\hline$\chi^{2}(211)$ & $2.5202 e-4$ & $2.8183 e-4$ & $6.0534 e-4$ \\
\hline & 6110 & 5627 & 13975 \\
\hline
\end{tabular}

Table 6.1: Estimated parameters. Standard errors are in parentheses. 
from switching out. The $\beta$ estimates match with Laibson, Repetto and Tobacman (2004), whose $\beta=0.7$.

In Table (6.1) the switching cost parameter $k$ is transformed into a dollar value. $k$ measures a utility value in the dynamic model. To interprete it intuitively, an approximate dollar value is calculated, dividing $k$ by the marginal utility at the average consumption level among the solicited population. For example, $k=0.0292$ corresponds to a dollar value of $\$ 292$. In another word, the mean of switching cost is $\$ 146$ which belongs to a uniform distribution $[0, k]$. The liquid asset distribution parameters, $\mu$ and $\epsilon^{2}$, are also transformed to facilitate estimation. Both estimated values and their corresponding dollar values are reported in Table (6.1).

Exponential consumers are estimated to have a much larger switching cost $k$, a larger mean $\mu$ and a larger variance $\epsilon^{2}$. Such parameters are required to better match the debt path over time. To match preference for the shorter offer, exponential consumers have to have a large $\delta, 0.9999$, as shown in the above simulation. Such patient exponential consumers are more likely to borrow under $16 \%$ APR only when they have a higher switching cost. With a higher switching cost, $\mu$ and $\epsilon^{2}$ have to change accordingly to match the magnitude of average debt and response rates.

All three models are decisively rejected by the over-identification test. However hyperbolic models are rejected to a lesser degree compared with the exponential model. The failure of this test is expected because of the large sample size, about 100,000 observations contributing to each moment. As the sample size becomes so large, any small misspecification will result in a rejection. Regardless of rejection, hyperbolic models still predict better than the exponential model.

Consumer responses to six different introductory offers are shown in Table (6.2). All three models match the response rates because we put a large weight on this moment. Hyperbolic models are better than the exponential model because they also predict that a higher response rate to the short offer $\mathrm{A}$.

In Fig.(6.1), the predicted debt paths of Market Cells A, E and F implied by 

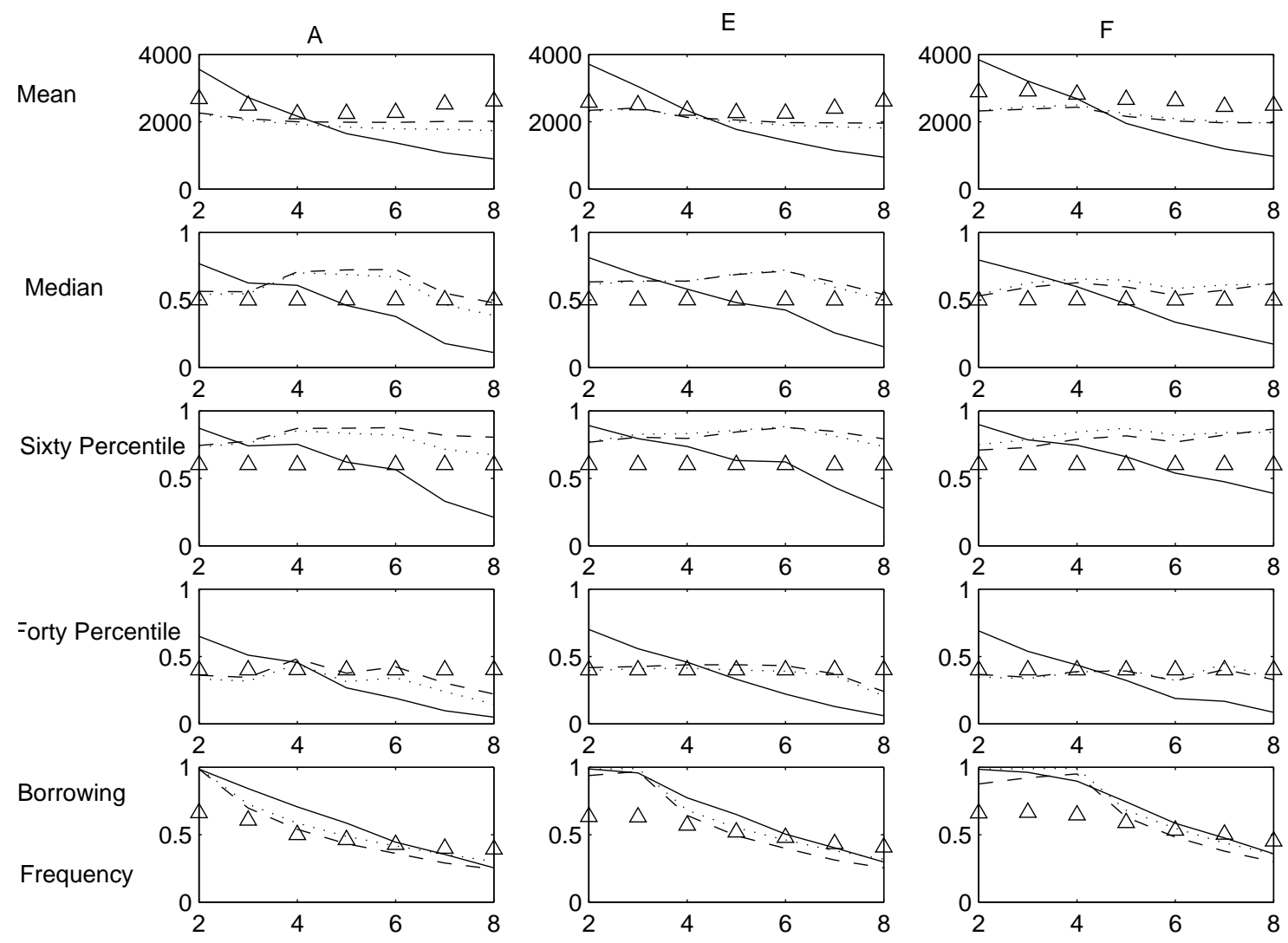

Figure 6.1: Simulated debt moments. The triangle line is the empirical data. The solid line, the dash line and the dotted line are predicted by the exponential, sophisticated and naive hyperbolic models respectively. 


\begin{tabular}{|c|c|c|c|c|c|}
\hline Market Cell & Total & Empirical & $\begin{array}{c}\text { Naive } \\
\text { Hyperbolic }\end{array}$ & $\begin{array}{c}\text { Sophisticated } \\
\text { Hyperbolic }\end{array}$ & Exponential \\
\hline A: $4.9 \% 6$ months & 99,886 & 1073 & 1013 & 1001 & 951 \\
B: $5.9 \% 6$ months & 99,872 & 903 & 911 & 888 & 845 \\
C: $6.9 \% 6$ months & 99,869 & 687 & 810 & 793 & 764 \\
D: $7.9 \% 6$ months & 99,880 & 645 & 701 & 652 & 672 \\
E: $6.9 \% 9$ months & 99,890 & 992 & 997 & 980 & 1005 \\
F: $7.9 \% 12$ months & 99,860 & 944 & 978 & 947 & 1047 \\
\hline
\end{tabular}

Table 6.2: Simulated response in six market cells for hyperbolic and exponential models.

the three models are compared with empirical data. Comparing to the exponential model, the two hyperbolic models match the debt path much better, which is the reason why their "Goodness-of-Fit" statistics are much lower. Despite a very large switching cost, the debt path predicted by the exponential model declines much faster than the data. Exponential consumers borrow too much at the beginning, an average of $\$ 3500$ compared with $\$ 2700$ empirically, and too little at the end, an average of $\$ 900$ instead of $\$ 2600$ empirically. Such a debt path is predicted because that exponential consumers are so patient $(\delta=0.9999)$ that they will pay off their debt even without switching. However a large $\delta$ is required to match consumer preference for the short offer.

The magnitude of $k$ deserves some discussion. Is the average switching cost $\$ 150$ outrageously high? The magnitude of $k$ here is consistent with anecdotal evidence in the credit card market. Credit card issuers spend lots of money to acquire one customer. Credit card companies send out billions of solicitations every year and $99 \%$ of them end up in trash cans. Many solicitations offer a very low introductory rate, as low as $0 \%$. The behavior of issuers will only be rational if majority consumers don't switch. In contrast to low acceptance rates, the average 
credit card debt is $\$ 9000$ among U.S. households with at least one credit card. ${ }^{2}$ This expensive inertia directly implies high disutility that consumers associate with card application, which is captured by switching cost $(k)$ in the dynamic model.

A close inspection of Fig.(6.1) reveals that there are two features of the data, which are not explained by the hyperbolic models. First, there are only $65 \%$ respondents borrowed during introductory duration. However both hyperbolic models predict that almost all respondents borrow at the beginning. Second, the predicted debt distribution is more concentrated than the empirical data, because there are significantly more respondents borrow more than the sixty percentile, about $75 \%$. We suspect this is due to the restrictive assumption of homogenous consumers. We observe that there are $20 \%$ respondents are convenience users, who never borrowed even in the introductory period. Their time preferences must be different from those revolvers, who borrow even under $16 \%$ interest rate. In the future research, we plan to explore the effect of consumer heterogeneity.

\subsection{Robustness}

In this section, we check the robustness of the above findings. First, can a time consistent model match empirical moments as well as hyperbolic models if it has an extra parameter $\beta$ ? To answer this question, we estimate a model whose discounting function is $\left\{1, \beta \delta, \beta \delta^{2}, \ldots\right\}$ at period 1 (solicitation time) and $\left\{1, \delta, \delta^{2}, \ldots\right\}$ at all later periods. This model is time consistent because the desired discount rate is the same $(\delta)$ between any two consecutive periods. But it has a one-time present bias factor at the card acceptance stage which may generate preference for the low-rate short offer A. The estimation result for this model is reported in the first column of Table (6.3). It is apparent that the extra parameter fails to improve fitness significantly. Actually, the optimal parameter $\beta$ is almost equal to 1 . It seems that

\footnotetext{
${ }^{2}$ Based on data from cardweb.com.
} 
time inconsistent preference is the key in order to match the empirical data, not one extra parameter.

Secondly, do the above findings still hold if Market Cell A is ignored? The above estimation critically depends on the assumption that consumers behave the same no matter which market cell they belong to. One possible criticism is that consumers in Market Cell A may not be comparable to consumers in other cells because offer A (4.9\% for 6 months) is an exceptionally good offer. The ordinary offer from the issuer is $\mathrm{B}$ ( $5.9 \%$ for 6 months). To address this concern we estimate the dynamic model based on consumer behavior on other five market cells. The estimation results are shown in the last three columns of Table (6.3). Still hyperbolic models match empirical moments better than the exponential model. When cell A is omitted, time inconsistency has reduced, therefore the difference between exponential and hyperbolic models has decreased. Specifically, the Goodness-of-Fit of the exponential model has improved because a lower $\delta$ is required to match response rates. And a lower $\delta$ improves prediction on debt path. The significant change for hyperbolic models are that a larger $\beta$ is needed to match response rates because the time inconsistency is reduced. 


\begin{tabular}{|c|c|c|c|c|}
\hline & Consistent $\beta$ & $\begin{array}{c}\text { Sophisticated } \\
\text { Hyperbolic }\end{array}$ & $\begin{array}{c}\text { Naive } \\
\text { Hyperbolic }\end{array}$ & Exponential \\
\hline Extra Parameter & Yes & No & No & No \\
\hline A is excluded & No & Yes & Yes & Yes \\
\hline \multirow[t]{2}{*}{$\beta$} & 0.9999 & 0.8034 & 0.8246 & \\
\hline & $(0.002967)$ & $(0.00253)$ & $(0.00255)$ & \\
\hline \multirow[t]{2}{*}{$\delta$} & 0.9999 & 0.9998 & 0.9999 & 0.9726 \\
\hline & $(0.002972)$ & $(0.00133)$ & $(0.00124)$ & $(0.000962)$ \\
\hline \multirow[t]{3}{*}{$k$} & 0.1722 & 0.0292 & 0.03266 & 0.0825 \\
\hline & $\$ 1,722$ & $\$ 292$ & $\$ 326$ & $\$ 825$ \\
\hline & $(0.0115)$ & $(0.000945)$ & $(0.00129)$ & $(0.00358)$ \\
\hline \multirow[t]{3}{*}{$\mu$} & 1.5836 & 1.0072 & 0.9752 & 1.4534 \\
\hline & $\$ 7,918$ & $\$ 5,036$ & $\$ 4,876$ & $\$ 7,267$ \\
\hline & $(0.0422)$ & $(0.0305)$ & $(0.0346)$ & $(0.02997)$ \\
\hline \multirow[t]{3}{*}{$\epsilon^{2}$} & 4.278 & 0.8377 & 0.8296 & 2.1854 \\
\hline & $\$ 42,780,000$ & $\$ 8,377,000$ & $\$ 8,296,000$ & $\$ 21,854,000$ \\
\hline & $(0.0437)$ & $(0.0393)$ & $(0.0514)$ & $(0.055)$ \\
\hline Goodness-of-Fit & $6.04892 e-4$ & $2.50492 e-4$ & $2.63716 e-4$ & $4.90161 e-4$ \\
\hline$\chi^{2}$ & 20840 & 3996 & 4482 & 10610 \\
\hline
\end{tabular}

Table 6.3: Robustness. 


\section{Chapter 7}

\section{Conclusion}

This thesis applies three different models of intertemporal choices to explain consumer behavior in a credit card market experiment, exponential, sophisticated hyperbolic and naive hyperbolic. From this unique dataset, two contradictory phenomena are observed. First, at the time of solicitation, consumers prefer an offer with a lower introductory interest rate (4.9\%) and a shorter duration (6 months), to an offer with a higher introductory interest rate (7.9\%) but a longer duration (12 months). The relative preference is puzzling since consumers would benefit more, ex post, from the longer introductory offer. We call it "rank reversal". Second, the majority of respondents do not switch out after the expiration of their introductory offers, even though their debt remains at the same level as when they accept the offer. This is puzzling because there are so many other offers available and the benefit of switching is as large as before.

We first use a multi-period complete information model to analytically prove that standard exponential consumers will not exhibit "rank reversal". Exponential consumers always prefer the credit card offer which incurs the least interest payment. However, if consumers are assumed to have time inconsistent preferences, such as the newly developed hyperbolic discounting, "rank reversal" is not a puzzle any more. We have explored two extreme types of hyperbolic discounting: naive and 
sophisticated. Both of them can explain the data, however the underlying stories are different. Naive consumers mistakenly prefer the shorter offer because they underestimate their future borrowing. Sophisticated consumers prefer the shorter offer because it offers a self-commitment device. Before this experiment, the standard laboratory experiments try to solicit consumer time preferences by offering them financial rewards at different time. Besharov and Coffey (2003), however, shows that this can't identify time inconsistent preferences because both consistent and inconsistent consumers would behave the same - maximize their wealth. The market experiment studied here provides a unique angle to identify hyperbolic discounting.

Can an exponential model with realistic random shocks explain the above two puzzles? To address this question, an incomplete information dynamic model is developed, in which consumers have both time consistent (exponential) and time inconsistent (hyperbolic) preferences and they are subject to realistic random shocks, such as income shocks. The estimation results based on this dynamic model show that still only the hyperbolic model can explain two phenomena simultaneously. The exponential model fails because that time consistent consumers would always prefer an offer which on average provides the lowest interest payment.

Another interesting finding is that when the present bias factor $\beta$ is close to 1, the two hyperbolic models, sophisticated and naive, behave similarly. We analytically illustrate this in a three-period complete information model. We also empirically observe this from the incomplete information dynamic model. This finding is interesting because the two models describe two fundamentally different consumers. Naive consumers fail to recognize they have time inconsistency problem. However, sophisticated consumers forsee their self-control problems. Naive models are as easy to compute as exponential models. On the other hand, sophisticated models may have multiple equilibria as proved in Krusell (2003). One direct application of this finding is that future research can use naive models to approximate sophisticated models if no welfare analysis involved, because the empirically relevant $\beta$ is close to 
1.

A time-varying switching cost is required to explain why respondents don't switch again after introductory offers expire. Accepting one offer only implies that respondents have low switching costs at the time of acceptance. Most of the time consumers face much higher switching costs. Therefore majority of them fail to switch a second time even though their debt remains large.

Consumer time consistency is an important question since different models have vastly different normative implications. For example a consumer piles up debt on her credit cards. She may do so because the pleasure of consumption today outweighs the interest payment tomorrow. Or she may do so because she has an impulse to overspend which is not valued from the long-run perspective, like the sophisticated agent. The two stories have different public policy implications. The first consumer just borrows the right amount. However, the second consumer would like somebody to bind her hands. It is crucial to distinguish between the two hypotheses.

Consumer behavior identified here also facilitates the understanding of competition anomalies in the credit card market. Instead of lowering interest rates, credit card issuers fiercely compete with each other by sending out "junk mail". $99 \%$ of direct solicitation mails end up in trash cans. Credit card companies offer ridiculously low introductory interest rates to acquire new customers, like $0 \%$ for 12 months. Nevertheless the post interest rate sticks around the prime rate plus $9.99 \%$. All these strategies are optimal only if consumers don't switch. This study not only provides individual-level evidence of this inertia, but also identify two separate forces behind it: self-control problems and high switching costs. 


\section{Appendix A}

Sign of $\frac{d A_{1}}{d \beta_{1}}$

In the complete information model,

$$
A_{1}=\frac{\left(y_{1}+A_{0}\right)-Z\left(y_{3}+r_{2} y_{2}\right)}{1+r_{1} r_{2} Z}
$$

where $Z=(F)^{-1 / \rho}$,

$$
F=\left[\beta_{0} \delta r_{1} r_{2}\left(\frac{X}{1+X r_{2}}\right)^{1-\rho}+\beta_{0} \delta^{2} r_{1} r_{2}\left(\frac{1}{1+X r_{2}}\right)^{1-\rho}\right]
$$

and $X=\left(\beta_{1} \delta r_{2}\right)^{-\frac{1}{\rho}}$. Here we show that $d A_{1} / d \beta_{1} \gtreqless 0$ when $\rho \gtreqless 1$.

\section{Proof:}

$$
\begin{aligned}
\frac{d A_{1}}{d \beta_{1}} & =\frac{d A_{1}}{d Z} \cdot \frac{d Z}{d F} \cdot \frac{d F}{d X} \cdot \frac{d X}{d \beta_{1}} \\
\frac{d A_{1}}{d Z} & =\frac{-\left[\left(A_{0}+y_{1}\right) r_{1} r_{2}+r_{2} y_{2}+y_{3}\right]}{\left(1+r_{1} r_{2} Z\right)^{2}}<0 \\
\frac{d Z}{d F} & =(-1 / \rho) \cdot(F)^{-1 / \rho-1}<0 \text { since } F>0 \\
\frac{d F}{d X} & =\left(\frac{1}{1+x r_{2}}\right)^{2-\rho}(1-\rho) \beta_{0} \delta^{2} r_{1} r_{2}^{2}\left(\beta_{1}-1\right) \\
\frac{d X}{d \beta_{1}} & =(-1 / \rho)\left(\beta_{1} \delta r_{2}\right)^{-1 / \rho-1} \delta r_{2}<0
\end{aligned}
$$

Apparently, the sign of $d A_{1} / d \beta_{1}$ is determined by the sign of $1-\rho$ because 
$\beta_{1}-1 \leq 0$

\section{Appendix B}

\section{Income Process}

Laibson et al. (2000) models the idiosyncratic income shock, $\xi_{t}$, as a sum of a persistent shock, $\mu_{t}$, and a transitory shock, $\nu_{t}$. The persistent shock follows an $\operatorname{AR}(1)$ process with a coefficient $\alpha$.

$$
\begin{aligned}
& \xi_{t}=\mu_{t}+\nu_{t}, \\
& \mu_{t}=\alpha \mu_{t-1}+\varepsilon_{t},
\end{aligned}
$$

where $\varepsilon_{t} \sim N\left(0, \sigma_{\varepsilon}^{2}\right)$ and $v_{t} \sim N\left(0, \sigma_{v}^{2}\right)$. He estimated $\alpha, \sigma_{\varepsilon}^{2}, \sigma_{v}^{2}$ for three different education levels. The parameters for "completed college" are used in the estimation.

Define a quarterly income shock, $\eta_{q}$, such that $\xi_{t}=\sum_{q=4(t-1)+1}^{4 t} \eta_{q}$.

$$
\begin{aligned}
& \eta_{q}=s_{q}+\epsilon_{q}, \\
& s_{q}=f s_{q-1}+\gamma_{q},
\end{aligned}
$$

where $s_{q}$ is a quarterly persistent shock with a coefficient of $f . \gamma_{q} \sim N\left(0, \sigma_{r}^{2}\right)$ and $\epsilon_{q} \sim N\left(0, \sigma_{\epsilon}^{2}\right)$.

It can be shown that:

$$
\begin{aligned}
& 4 \sigma_{\epsilon}^{2}=\sigma_{v}^{2} \\
& \frac{1}{1-\alpha^{2}} \sigma_{\varepsilon}^{2}=\left(4+6 f+4 f^{2}+2 f^{3}\right) \frac{\sigma_{r}^{2}}{1-f^{2}} \\
& \frac{\alpha}{1-\alpha^{2}} \sigma_{\varepsilon}^{2}=\left(f+2 f^{2}+2 f^{3}+4 f^{4}+3 f^{5}+2 f^{6}+f^{7}\right) \frac{\sigma_{r}^{2}}{1-f^{2}}
\end{aligned}
$$

After obtaining parameters for the quarterly shock, we use a two-state Markov process to replace the $s_{q}$ which follows an $\mathrm{AR}(1)$, following Laibson et al. (2000). 
The Markov process is symmetric taking two values $\{\theta,-\theta\}$, where $\theta=\sqrt{\frac{\sigma_{r}^{2}}{1-f^{2}}}$ and the transition probability $p=\frac{1+f}{2}$. In this way the Markov process matches the variance covariance of $s_{q}$.

Recall the income process in the dynamic model, $y_{t}=\varphi_{t} y_{t}^{g}+\left(1-\varphi_{t}\right) y_{t}^{b} \cdot y_{t}^{j}$ is lognormal random variable, where $j \in\{g, b\}$ and $\varphi_{t}$ is a signal whether the income state is good or bad.

$$
\begin{aligned}
& \log \left(y_{t}^{g}\right)=c+\theta+\epsilon_{t} \\
& \log \left(y_{t}^{b}\right)=c-\theta+\epsilon_{t}
\end{aligned}
$$

where $c$ is a constant to capture the permanent income. To determine $c$, I assume the mean income is $\$ 10,000$ per quarter.

In summary, the income process in the good state has a mean of 10,000 and a variance of $3.5 \times 10^{5}$. The income process in the bad state has a mean of 7645 with a variance of $2.05 \times 10^{5}$. The transition probability matrix is:

$$
p=\left(\begin{array}{ll}
0.9939 & 0.0061 \\
0.0061 & 0.9939
\end{array}\right)
$$




\section{BIBLIOGRAPHY}

[1] Ainslie, George and Varda Haendel, "The Motives of the Will," In E. Gotteheil et al. (eds.), Etiologic Aspects of Alcohol and Drug Abuse, Springfield, Il, Thomas, 1983.

[2] Akerlof, George A, "Procrastination and Obedience," American Economic Review, Papers and Proceedings, May, 1991 1-19.

[3] Ausubel, Larry M., "The Failure of Competition in the Credit Card Market," American Economic Review, March, 1991, 50-81.

[4] Ausubel, Larry M., 1999. "Adverse Selection in the Credit Card Market," working paper, University of Maryland.

[5] Besharov, Gregory and Bentley Coffey, "Reconsidering the Experimental Evidence for Quasi-Hyperbolic Discounting," working paper, Duke University, 2003.

[6] Carroll, Christopher D., "The Buffer Stock Theory of Saving: Some Macroeconomic Evidence," BPEA, 1992, 2, 61-156.

[7] Carroll, Christopher D., "Buffer-Stock Saving and the Life Cycle/Permanent Income Hypothesis," Quarterly Journal of Economics, 1997, 112, 1-57. 
[8] Deaton, Augus, "Saving and Liquidity Constraints," Econometrica, 1991, 59, $1221-48$.

[9] Della Vigna, Stefano, and M. Daniele Paserman 2000. "Job Search and Hyperbolic Discounting," Harvard University mimeo.

[10] Della Vigna, Stefano and Ulrike Malmendier 2002. "Self-Control in the Market: Evidence from the Health Club Industry," Harvard University mimeo.

[11] Diamond, Peter and Botond Koszegi 2003. "Hyperbolic Discounting and Retirement," MIT mimeo.

[12] Fernandez-Villaverde, Jesus and Arijit Mukherji 2002. "Can We Really Observe Hyperbolic Discounting?" University of Pennsylvania mimeo.

[13] Fang, Hanming and Dan Silverman 2001. "Time-inconsistency and Welfare Program Participation: Evidence from the NLSY," Yale University mimeo.

[14] Gruber, Jonathan and Botond Koszegi 2001. "Is Addiction 'Rational'? Theory and Evidence," Quarterly Journal of Economics, November, 116(4), 1261-1303.

[15] Hall, George and John Rust 2002. "Econometric Methods for Endogenously Sampled Time Series: The Case of Commodity Price Speculation in the Steel Market," Yale University mimeo.

[16] Hansen, L. P. 1982. "Large Sample Properties of Generalized Method of Moments Estimators," Econometrica, 50, 1929-1954.

[17] Harris, Christopher and David Laibson 2001. "Dynamic Choices of Hyperbolic Consumers," forthcoming in Econometrica.

[18] Imrohoroglu, Ayse, Selahattin Imrohoroglu and Douglas H. Joines 2003. "Time-inconsistent Preferences and Social Security," Quarterly Journal of Economics, 118(2), 745-84. 
[19] Laibson, David I. 1997. "Golden Eggs and Hyperbolic Discounting," Quarterly Journal of Economics, 62(2), 443-478.

[20] — - Andrea Repetto, and Jeremy Tobacman 1998. "Self-Control and Saving for Retirement," Brookings Papers on Economic Activity, 1, 91-196.

[21] — — — , and — 2000. "A Debt Puzzle," in eds. Philippe Aghion, Roman Frydma, Joseph Stiglitz, Michael Woodford, Knowlege, Information and Expectation in Modern Economics: In Honor of Edmund S. Phelps, forthcoming.

[22] Loewenstein, Geoge and Richard H. Thaler 1989.

[23] Loewenstein, G. "Out of control: visceral influences on behavior," Organizational Behavior and Human Decision Processes, 1996, 65, 272-92.

[24] Miravete, Eugenio J. 2003. "Choosing the Wrong Calling Plan? Ignorance and Learning," American Economic Review, 93(1), 297-310.

[25] Mulligan, Casey. 1997. “A Logical Economist's Argument Against Hyperbolic Discounting," University of Chicago mimeo.

[26] O'Donoghue, Ted and Matthew Rabin 1999. "Doing it Now or Later," American Economic Reviewb, March, 89(1), 103-124.

[27] — 2001 "Choice and Procrastination." Quarterly Journal of Economics, 116(1), 121-160.

[28] Paserman, Marco Daniele 2003. "Job Search and Hyperbolic Discounting: Structural Estimation and Policy Implications." Manuscript, Hebrew University of Jerusalem.

[29] Read, Daniel and Barbara van Leeuwen, "Predicting Hunger: The Effects of Appetite and Delay on Choice." Organizational Behavior and Human Decision Processes, 1998, 76(2), 189-205. 
[30] Rubinstein, Ariel. 2000. "Is It 'Economics and Psychology'?: The Case of Hyperbolic Discounting," Princeton University mimeo.

[31] Strotz, R. H. 1956. "Myopia and Inconsistency in Dynamic Utility Maximization," Review of Economic Studies, 23, 165-80.

[32] Thaler, Richard. 1981 "Some Empirical Evidence on Dynamic Inconsistency," Economics Letters, 8, 201-207. 